\title{
The Importance of Considering Religious and Spiritual Ontologies in the Care of HIV Patients in Zimbabwe - A Scoping Literature Review
}

\author{
Ursula Wuthrich Grossenbacher ${ }^{1,}$, Julia Mutambara ${ }^{2}$, Nicholas Midzi ${ }^{3}$, Masceline Mutsaka ${ }^{3}$ \\ ${ }^{1}$ Center for African Studies, University of Basel, Basel, Switzerland \\ ${ }^{2}$ Psychiatry Department, Midlands State University, Gweru, Zimbabwe \\ ${ }^{3}$ National Institute of Health Research, Harare, Zimbabwe
}

Email address:

u.wuethrich@stud.unibas.ch (U. W. Grossenbacher)

${ }^{*}$ Corresponding author

\section{To cite this article:}

Ursula Wuthrich Grossenbacher, Julia Mutambara, Nicholas Midzi, Masceline Mutsaka. The Importance of Considering Religious and Spiritual Ontologies in the Care of HIV Patients in Zimbabwe - A Scoping Literature Review. International Journal of HIV/AIDS Prevention, Education and Behavioural Science. Vol. 7, No. 1, 2021, pp. 27-47. doi: 10.11648/j.ijhpebs.20210701.14

Received: April 29, 2021; Accepted: May 27, 2021; Published: June 4, 2021

\begin{abstract}
Background: HIV continues to have a major impact on morbidity and mortality in Zimbabwe. Religion/Spirituality (R/S) including traditional beliefs and practices (TP) play an important role for most people living with HIV (PLWHIV) in Zimbabwe. PLWHIV conceive and practice healing holistically, embracing not only the physical conditions, but also the spiritual, psycho-emotional, social, and ecological dimensions. Objective: This scoping review aims to systematically map the research done around R/S and TP and HIV in Zimbabwe. It intends to describe what is known about the role and influence of R/S on the experience of living with HIV in Zimbabwe in general and especially, to illustrate the influence of R/S and TP on the physical and psychological wellbeing of PLWHIV, and the access to HIV care. Design: This scoping review followed the Joanna Briggs Institute's guidelines. The online databases Medline \& ATLA were used to identify articles published between 2010-2021 about R/S and TP and HIV in Zimbabwe. The review includes textual papers, qualitative, quantitative, and mixed studies. Results: 638 records were found and screened for inclusion. 46 records were considered relevant for the qualitative and quantitative synthesis. Most articles (27) addressed the influence of traditional beliefs and practices on health and HIV and 16 records examined the influence of religious beliefs and religious groups' attitude on HIV. The qualitative synthesis illustrates the influence of R/S and TP on physical and psychological wellbeing and on access to HIV care of PLWHIV in Zimbabwe, thus portraying the medical relevance of R/S issues and TP. Further synthesis identified three areas of conflict with biomedical practice: The bio-psycho-socio-spiritual understanding of health and illness, the notion of patriarchy, and the perception of sexuality and procreation. Here religious/spiritual ontologies may lead to compromised biomedical therapy outcomes. Conclusion: This scoping review includes papers of authors from different backgrounds (theology, medicine, sociology). The synthesis of the content of the records revealed a coherent picture of themes addressed and problems identified. Thus, this review is a fair description of the experience of living with HIV in Zimbabwe and the medical relevance of R/S and TP. The findings show that religious/spiritual ontologies need to be considered and integrated into the design of new health programs. It must be the aim to avoid compromised therapy outcome and to further a holistic support of PLWHIV. This is only possible in collaboration with religious stakeholders and traditional practitioners.
\end{abstract}

Keywords: HIV, AIDS, Religion, Traditional Practice, Zimbabwe 


\section{Introduction}

\subsection{Background}

With a prevalence of about $12.7 \%$ [1] among adults aged 15 to 49 years, human immunodeficiency viruses (HIV) continues to have a major impact on morbidity and mortality in Zimbabwe. Although $85 \%$ of PLWHIV are on ART, only $73 \%$ have a suppressed viral load [1]. Thus, attrition from antiretroviral therapy (ART) remains a serious challenge [2]. Therefore, new methods of care are needed that address risk factors and protective factors to ART adherence that have not been considered sufficiently.

In Zimbabwe religion/spirituality (R/S) plays a major role in daily life, substantially influencing people's health behaviour. Research by Shoko et al explain that in the Shona understanding, healing is conceived and practiced holistically, it includes not only the physical condition, but also spiritual, psycho-emotional, social and ecological dimensions [3]. As health is often seen as a gift from God, $\mathrm{R} / \mathrm{S}$ and healing are intrinsically intertwined [4]. Ten percent of the respondents of a demographic health survey conducted in 2012 indicated that they thought it was possible to contract HIV from witchcraft or other supernatural means [5]. O'Brien and Broom rightly point out that if the origin of a disease is not framed biomedically, then biomedical treatment is less likely to be appreciated or enacted [6].

In Harare it has been observed that religious affiliation influenced women's readiness for cervical cancer screening [7]. According to the demographic health survey, most Zimbabweans would call themselves 'Christian' [5]. Many different types of Christianity and many Christian sects exist in Zimbabwe. Studies have highlighted that church affiliation is an important factor to the response to HIV [8]. While some churches advocate antiretroviral therapy (ART) of HIV infection as a gift from God, others do not allow biomedical aid, some stigmatize people living with HIV/AIDS (PLWHA), and some emphasize prayer healing [9]. During Africaid/Zvandiri's most recent study in 2016-2017 among adolescents with HIV in Zimbabwe, up to $73 \%$ of deaths were due to cessation of ART sanctioned by caregivers, probably motivated by faith healing [10]. The World Council of Churches (WCC) recognizes faith healings as a major obstacle in HIV care [9]. In 2002, the WCC highlighted "harmful cultural practices and theological and ethical fault lines in the practice of ministry in the churches and theological institutions" [11].

Local researchers [12] published a paper last year stating that people living with HIV (PLWHIV) in Gweru Zimbabwe defaulted medications because they believed in faith healing, alternative medicines, perceived spirituality as the main cause of HIV and AIDS. Furthermore, they had an allegiance to church values. They showed the need to provide HIV and AIDS education to leaders of religious organizations so as to harmonize religion and HIV and AIDS treatment [12]. The importance of finding ways to engage R/S stakeholders in HIV care is also highlighted by Becker \& Geissler who argue that religious groupings are instrumental in, instrumentalised by, and instrumentalising the organisation of HIV-related interventions [13]. There is at least one example where a church in Zimbabwe successfully initiated a rural community program to support PLWHIV in a tripartite partnership consisting of the Mission Hospital staff, the Church, and the community (including schools, villages, local chiefs, and a village headmen) [14].

Stigma, violence and intimate partner violence (IPV) are very important factors that have been shown to increase risk of HIV infection and lower medication adherence. [15] While such insight is important, it is crucial not only to identify the factors influencing adherence, but also to learn about the underlying root causes (beliefs, norms and attitudes behind the factors) leading to stigma and IPV. One discriminating name for HIV/AIDS in Zimbabwe is 'chirwere chepfambi' meaning 'disease of prostitutes'. It was suggested that the stigmatisation of prostitutes as carriers of the virus, as opposed to their clients, may signal a general belief about women whose sexuality is not under the control of male partners, fathers or elders [16]. Blaming and stigmatisation is very common. In Zimbabwe Homosexuals are not only stigmatized, but also criminalized [17].

In addition to religion as an influence, many Zimbabweans consult Traditional Practitioners (TP) for health-related issues and spiritual problems. The choice to consult TP and to use herbal medicines is usually based on various factors; the primary ones being inaccessibility and unaffordability of western medicine coupled with a strong belief in herbs as effective, affordable and accessible [18]. People readily combine Christian beliefs and rituals with aspects of traditional culture and religion [19]. Western medicine, traditional practices, herbal medicine, as well as faith healings are often used simultaneously. A recent exploratory qualitative study in six eastern and Southern African countries has shown that medical pluralism, manifesting across traditional, faith-based and biomedical health-worlds, contributes to delays and interruptions of care along the HIV cascade, as well as mistrust between health providers. It is argued that the role of sociocultural beliefs necessitates the adoption of culture-sensitive approaches, intervention designs and policy reforms [20].

Integrating TP into the HIV care could be an opportunity to benefit from their useful herbs and therapies, while offering the chance to dispel practices that might exacerbate the spread of HIV. While herbal medicine has the potential to reduce adverse drug reactions to ART, some herbal formulations have been identified as having pharmacokinetic interactions with antiretroviral drugs [21]. Also, some traditional healing methods, like the frequent use of skin cutting gadgets, might further the spread of HIV [22]. Batisai argues that integration of the western and traditional medical systems might be complementary in their merits and achieve what neither would alone [18].

\subsection{Rational for Scoping Review}

So far, R/S issues and TP are hardly considered in the 
biomedical approach in Zimbabwe. TP and religious stakeholders are not officially integrated into the HIV care. A preliminary search for existing scoping reviews on the topic of R/S and HIV in Zimbabwe was conducted on the $18^{\text {th }}$ of January 2021 in Epistemonikos and Pubmed without result. There are several individual, mainly qualitative, studies with relevant results. Many of these studies have been known by the authors of this study and are included in the introduction. However, the body of literature has not yet been comprehensively reviewed and thus it seems these results stand alone. Therefore, a scoping review was conducted to systematically map the research done in this area and to summarize and synthetize the findings of the different authors of various fields of expertise (theology, medicine, sociology). The findings allowed a fair description of the influence and medical relevance of R/S and TP for PLWHIV in Zimbabwe that should be recognized by the stakeholders of all three health sectors (religious, traditional and biomedical).

\section{Review Question}

What is the role/influence of religion/spirituality $(\mathrm{R} / \mathrm{S})$ and traditional practice (TP on people living with HIV (PLWHIV) in Zimbabwe? Sub questions: What are enhancing or deterring $\mathrm{R} / \mathrm{S}$ and TP factors affecting HIV therapy and related health outcomes? What are the religious/spiritual ontologies that are foundational of specific beliefs and social norms (=underlying root causes beliefs, norms and attitudes)? What are the challenges and opportunities for engaging $\mathrm{R} / \mathrm{S}$ and TP stakeholders in HIV care?

\section{Inclusion Criteria}

Religious, cultural, and economic landscapes are dynamic and diverse. This is especially true for Zimbabwe's economic situation. To get a meaningful result, this scoping review focusses on Zimbabwe only. There are various descriptions, interpretations and meanings for the terms "religion" and "spirituality". In this paper the term "religion" refers to organised and/or shared faith practice or belief and the term "spirituality" refers to the way people relate to the transcendent, including traditional practices and beliefs.

HIV/AIDS remains a primary concern in Zimbabwe. Therefore, the paper focusses on HIV/AIDS. The nationwide rollout of ART in Zimbabwe in 2008-2012 has changed the perception of HIV/AIDS from being a death sentence. This might influence the role of R/S for HIV patients. Consequently, the review only includes papers published after 2009 .

\section{Review Objective}

The objective of this scoping review is to systematically map the research published in this area, to describe what is known about the role and influence of $\mathrm{R} / \mathrm{S}$ on the experience of living with HIV in Zimbabwe in general, and especially to illustrate the influence of R/S and TP on the physical and psychological wellbeing of HIV patients and the access to HIV care. The review further seeks to identify religious/spiritual ontologies that are foundational of specific beliefs and social norms that have a negative impact on PLWHIV in Zimbabwe and to show ways of how to mitigate this.

\section{Methodology}

This section documents how the reviewers searched for relevant sources of information for inclusion in the scoping review. It describes the individual research strategies for the two databases, documented in the Appendix.

\subsection{Search Strategy}

The preliminary search for existing scoping reviews on the topic of R/S and HIV in Zimbabwe in Epistemonikos and Pubmed yielded no result.

Reasons for choosing MEDLINE and ATLA databases: For the initial search, Pubmed database was chosen because it contains citations not only from the biomedicine and health fields, but also from related disciplines. The final search was then done in MEDLINE because of the added value of using the National Library of Medicine (NLM) controlled vocabulary, Medical Subject Headings (MeSH $\left.{ }^{\circledR}\right)$, to index citations. This allowed for a more focused search, avoiding citations that are out of scope. ATLA religious database was chosen because it is believed to be the premier index for literature in all fields of religion and theology.

Composing of search strings: The first step was an initial limited search in Pubmed and ATLA for papers including religion or faith or belief or tradition and HIV or Aids and within Zimbabwe. This initial search was then followed by an analysis of the text words contained in the title and abstract of the retrieved papers, and of the index terms used to describe the articles. Yale MeSH analyzer (https://mesh.med.yale.edu/) and (cgi-bin/miner/miner2.cgi) were used to find additional relevant MeSh terms. All identified words and terms were then combined in the search string to use for the search in the Medline database (Appendix: Doku Suchstring). The search identified 616 records. An information specialist of Basel University translated the search string for the search in ATLA (Appendix: Doku Suchstring) and the search in the ATLA database identified 22 records. There were no duplicates. The search in both databases was conducted on the 8th of February 2021.

\subsection{Study Screening and Selection}

All 638 records were screened for the source of evidence. Only primary studies, population survey studies, textual papers and reviews were included. Further criteria were:

1. Record needed to be relevant for Zimbabwean context (study population from Zimbabwe, or text about Zimbabwe)

2. The title or abstract needed to address one or more of the following themes: 
a. The role/influence of religion/spirituality $(\mathrm{R} / \mathrm{S})$ (including traditional beliefs and practices) on HIV patients.

b. Enhancing or deterring R/S factors affecting HIV therapy and related health outcomes.

c. Underlying root causes beliefs, norms and attitudes leading to $\mathrm{R} / \mathrm{S}$ factors affecting HIV therapy and related health outcomes.

d. Challenges and opportunities for engaging R/S stakeholders and traditional practitioners in HIV care

The screening was done individually by the two reviewers. Discrepancies were discussed using the selection criteria. Out of the 92 references that met the selection criteria, 43 references were considered to be only widely or indirectly connected and therefore excluded and 49 references were selected as directly relevant for full text screening.

Four additional records were found by searching the reference list of identified articles. There were no additional records through contact with authors.

Seven records were dismissed because they did not directly relate to HIV, the data was too old, or the approach did not meet the scientific requirements (due to the small case load and the conduct of interviews with closed questions).

\section{Analysis and Presentation of Results}

46 records were used for the qualitative and quantitative synthesis.

\subsection{Quantitative Synthesis}

Firstly, we mapped the records according to the characteristics. Four records were textual papers and all others were studies. Table 1 groups the studies into qualitative studies, mixed studies and quantitative studies, and also indicates the individual case load and the means of data generation.

Study Type: Most of the studies, namely 24, were qualitative studies, followed by 13 studies with a mixed approach and 4 quantitative studies out of which, 3 were population-based studies.

Means of data collection: The main data source were interviews, followed by Focus Group Discussions (FGD). Semi-structured interviews (SSI), in-depth interviews (IDI) and key informant interviews (KII) were used in 34 studies $(=74 \%)$. This is not surprising, as religion/spirituality $(\mathrm{R} / \mathrm{S})$ and traditional practice (TP) are a social phenomenon, and of a personal nature. Focus Group Discussions were used in more than a third of the studies.

Population: The people interviewed were predominantly Zimbabwean, people living with HIV (PLWHIV) and key informants (KII). Key informants are people who are affected by HIV (for example, parents, religious leaders, teachers and traditional practitioners). The respondents were adolescents and adults, including men and women as well as a few transgender participants.

First author R/S and TP are shaped by local context. Comprehensibly most of the first authors (more than two thirds) have an African background and some were able to conduct the interviews in the local language.

Setting: All studies included were done in Zimbabwe or used statistical data from Zimbabwe.

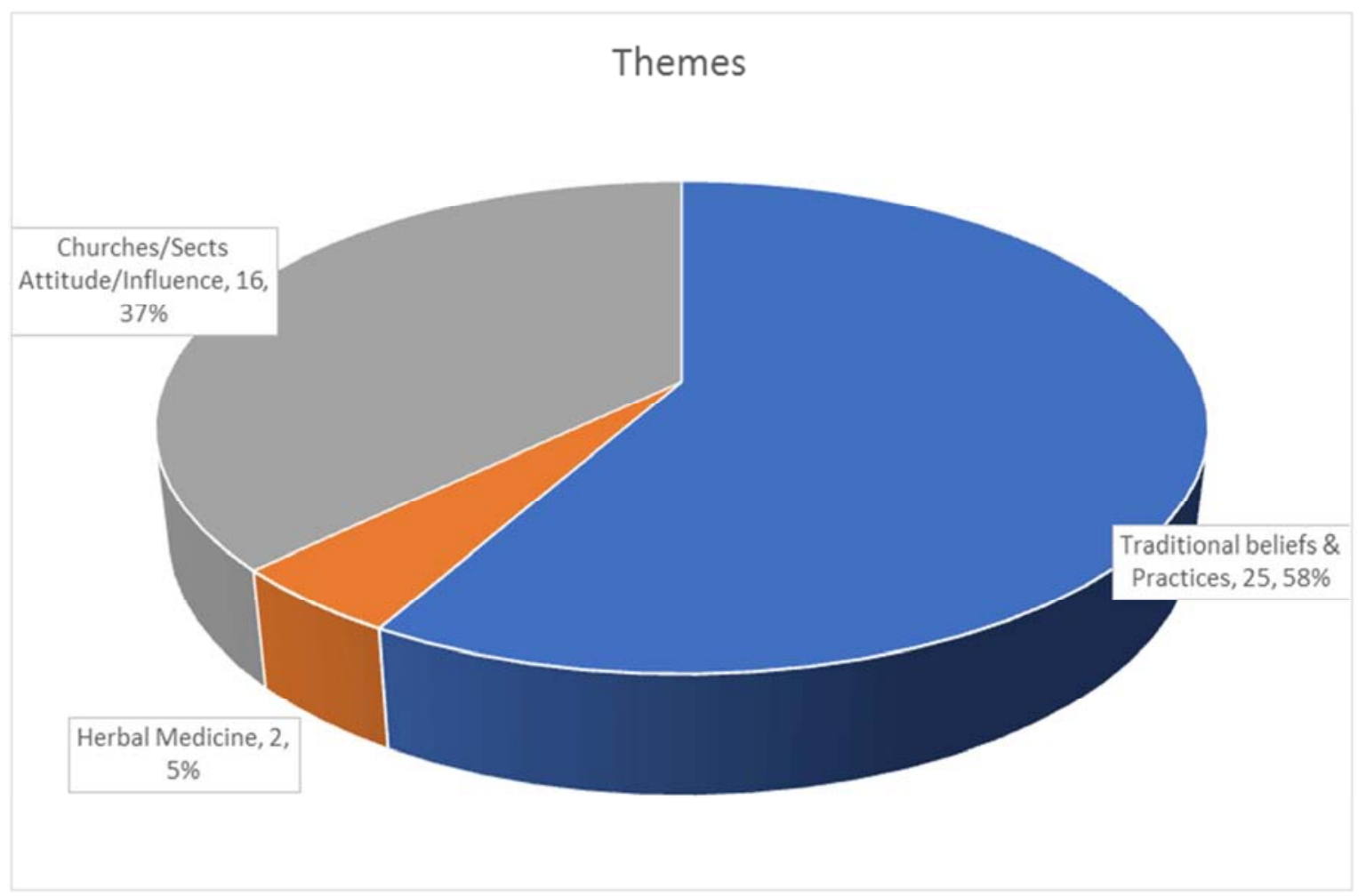

Figure 1. Records' Themes Mapping. 
Table 1. Study Type Mapping

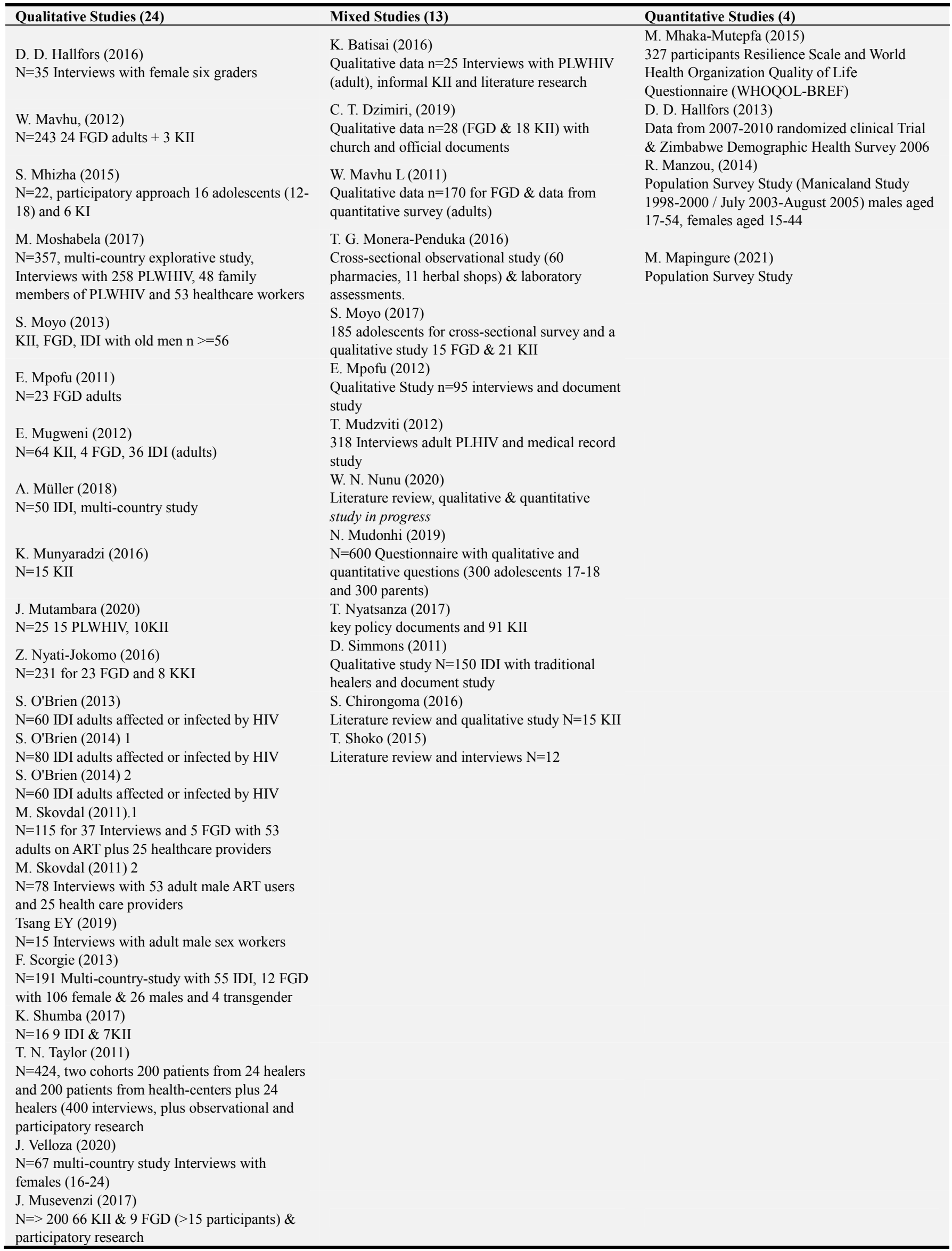




\begin{tabular}{lcc}
\hline Qualitative Studies (24) & Mixed Studies (13) & Quantitative Studies (4) \\
\hline J. Marashe (2014) & \\
N=18 8 questionnaires with KI, 10 KII \& FGD & \\
S. O'Brien (2014) 1 & \\
N=80 IDI adults affected or infected by HIV & \\
\hline
\end{tabular}

Articles/texts (total 5): Machingura F. (2011), V. Magezi and P. Manzanga (2020), C. Banda and S. Mudzanire (2019), I. Mhike \& E. K. Makombe (2018), M. Machinga (2011)

Figure 2 shows the records according to their content. The majority of records (25) addressed the influence of traditional beliefs and practices regarding health and HIV. Due to the fact that this study is interested in the medical relevance of $\mathrm{R} / \mathrm{S}$ and TP, the two records investigate the effect and use of herbal medicine are listed separately. Sixteen records examined the influence of religious beliefs and religious groups' attitude on HIV (=Churches/Sects).

\subsection{Qualitative Synthesis}

To identify the information available in literature regarding the influence of Religion/Spirituality \& Traditional Practice, this section presents a descriptive qualitative content analysis, including basic coding of data. As the selected studies cover different fields of expertise (sociological, theological, anthropological, medical) the Framework Method [22] was used to analyze and identify the different themes of the studies. The framework created a structure to summarize and synthetize the studies' content. The founder and director of the George Washington Institute for Spirituality and Health, explains that spirituality and religion are medically relevant, if a spiritual issue leads to distress or suffering (e.g. lack of meaning, conflicting religious beliefs, inability to forgive). The spiritual issue is the cause of a psychological or physical diagnosis (such as depression, anxiety, acute or chronic pain) or is a secondary cause, or affects the presenting psychological or physical diagnosis (e.g. refusal or delaying of therapy because of religious beliefs) [23].

Leaning on this understanding of the medical relevance of spiritual/religious issues, the themes were grouped into the following eight categories: The role/influence of R/S \& TP on HIV patients; Enhancing R/S \& TP factors; Deterring R/S \& TP factors; Root causes, beliefs, norms, attitudes; Challenges for engaging $\mathrm{R} / \mathrm{S}$ stakeholders in HIV care; Challenges for engaging TP in HIV care; Opportunities for engaging R/S stakeholders in HIV care; Opportunities for engaging TP in HIV care.

Quotes of the 46 studies were coded (=key findings), reassembled and summarized or grouped in codes and then assigned to one of the eight categories. This process was repeated and refined until both researchers agreed with the result.

Table 2. Codes (categories and subthemes) and Key Findings.

\begin{tabular}{|c|c|c|}
\hline Codes & Key Findings & Studies \\
\hline \multicolumn{3}{|c|}{ Category: The role/influence of R/S \& TP on HIV Patients } \\
\hline Beliefs about Health: & disease and illness are categorized according to cause & {$[6,18,24-27]$} \\
\hline \multirow[t]{16}{*}{ Bio-psycho-social-spiritual } & treatment according to cause of illness & {$[18,24,26]$} \\
\hline & Herbal remedies are chosen because they are endemic & {$[18]$} \\
\hline & breaching taboos, especially sexual ones, results in illness & {$[18,26,28]$} \\
\hline & HIV is linked to witchcraft & {$[26,29]$} \\
\hline & Bad luck, difficulties have spiritual cause & {$[26,30]$} \\
\hline & Serious illness carries social stigma - fear of hospitalization & [29] \\
\hline & Death of illness is will of God & {$[27]$} \\
\hline & Illness as alert to search for spiritual cause & {$[6]$} \\
\hline & illness caused by contact or contamination by, substance considered unclean or impure & [25] \\
\hline & Mixing blood of different constitutions linked to HIV & {$[25]$} \\
\hline & Health, disease sickness have spiritual foundations & {$[12,24,25,31-33]$} \\
\hline & Shona believe ancestral spirits influence health & {$[6,26,31]$} \\
\hline & Health=blessing from God and sickness $=$ curse from devil & [31] \\
\hline & Sickness as reason to join Spiritualist church & [8] \\
\hline & Only Holy Spirit can heal & {$[25]$} \\
\hline & Use of biomedicine shows lack of faith & {$[25]$} \\
\hline \multirow[t]{9}{*}{ Church Role } & Churches Leaders Association finding solutions to HIV problem & [14] \\
\hline & Successful church community program & {$[14,35]$} \\
\hline & $\begin{array}{l}\text { Prophets intercede between living and Spirit world and can drive out demons that cause } \\
\text { illness }\end{array}$ & {$[30,36]$} \\
\hline & Ultimate goal of church is spiritual health of its members & {$[33,36]$} \\
\hline & Church has a healing mandate & [37] \\
\hline & Church considered alternative health care system & {$[25,36]$} \\
\hline & metaphysical explanations for health give church control of members' health & [36] \\
\hline & $\begin{array}{l}\text { Christian Hospitals and Churches cared for PLWHIV from Beginning=role model for } \\
\text { government }\end{array}$ & {$[25,35]$} \\
\hline & Missions played important role in care of rural HIV patients & [37] \\
\hline
\end{tabular}




\begin{tabular}{|c|c|c|}
\hline Codes & Key Findings & Studies \\
\hline \multirow{9}{*}{$\begin{array}{l}\text { Churches' influence on } \\
\text { sexual \& health seeking } \\
\text { behaviour }\end{array}$} & Church did not reach out to apostolic sect members & [25] \\
\hline & $\begin{array}{l}\text { Church networked with authorities - police turns a blind eye on crimes in within churches } \\
\text { (e.g. child marriages) }\end{array}$ & [38] \\
\hline & Church silent on socio-cultural issues (intimate partner violence) & [39] \\
\hline & \multicolumn{2}{|l|}{ different beliefs, teachings and practices on sexual \& health } \\
\hline & seeking behaviour & [32] \\
\hline & Christian teachers required to teach abstinence & {$[26,37]$} \\
\hline & Less sexual partners among Christians & [32] \\
\hline & No teaching about contraceptive use for adolescents & [38] \\
\hline & No contraceptive use for some & {$[30]$} \\
\hline \multirow{7}{*}{$\begin{array}{l}\text { Religion determinant of } \\
\text { response to HIV epidemic }\end{array}$} & $\begin{array}{l}\text { The anti-medical approach of the Johanne Marange Church has been weakened by FBO } \\
\text { interventions }\end{array}$ & [27] \\
\hline & Sex outside marriage is sin & [26] \\
\hline & Churches played important role in reduction of HIV risk & {$[8,41]$} \\
\hline & Number of sexual partners linked to religious affiliation & [8] \\
\hline & HIV is seen as God's punishment for fornication & {$[12,29]$} \\
\hline & Homosexuality is $\sin$ & [29] \\
\hline & Spiritual beliefs influence the way HIV is understood and form of help sought & [6] \\
\hline \multirow{7}{*}{ Traditional Practitioners } & HIV is God's punishment for defiant sexual behaviour & {$[12,29,32]$} \\
\hline & Adolescents cannot disclose sexual activity and/or access PrEP & [41] \\
\hline & Medical versus traditional \& religious male circumcision & {$[42,43]$} \\
\hline & Evidence that opinions of traditional practitioners can influence medication choices & {$[6,33,44]$} \\
\hline & Traditional knowledge contributes information about herbal products & [44] \\
\hline & $90 \%$ of healers treat STIs & [28] \\
\hline & $\begin{array}{l}\text { Objective of healing is twofold: to identify the underlying cultural causes of sickness and } \\
\text { misfortune and to alleviate the physical pain and suffering }\end{array}$ & {$[4,24,26]$} \\
\hline & $\begin{array}{l}\text { six types of n'anga — spirit mediums, diviners, herbalists, faith healers, midwives, and } \\
\text { injectionists (nonspiritual healers) - each of which practices a distinct genre of healing }\end{array}$ & [4] \\
\hline \multicolumn{3}{|c|}{ Category: Enhancing R/S Factors } \\
\hline \multirow[t]{7}{*}{ Biblical ethos } & Using biblical ethos in support of HIV care & [14] \\
\hline & Compassion as religious obligation "faith without actions is dead & [14] \\
\hline & Services are free of charge & [31] \\
\hline & Healing mandate of churches & [37] \\
\hline & Church lead community program for palliative care & [14] \\
\hline & Church providing spiritual care to HIV patients & {$[14,35]$} \\
\hline & People joined church for spiritual healing & {$[45,36]$} \\
\hline \multirow[t]{9}{*}{ Coping } & Spirituality as coping factor & [46] \\
\hline & Acceptance of self and life & [46] \\
\hline & Best support for carers (=grandparents) by Church members & [46] \\
\hline & Praying to God when faced with insurmountable difficulties & {$[30]$} \\
\hline & Use of religious or spiritual strategies as coping mechanism & [30] \\
\hline & Visiting TP for spiritual remedies in distress & [30] \\
\hline & membership gives sense of belonging, purpose, and community & {$[14,36,46]$} \\
\hline & Religiosity fosters social cohesion & {$[45]$} \\
\hline & Trust, quality relationships & [46] \\
\hline \multicolumn{3}{|c|}{ Category: Deterring R/S factors } \\
\hline \multirow[t]{18}{*}{ Apostolic Churches } & Apostolic Church members are not allowed to use medicine & {$[18,25,31,42]$} \\
\hline & Increased risk of HIV infection for women & {$[25,31,36,45,47]$} \\
\hline & Child marriages common & {$[33,36,38,45]$} \\
\hline & Pressure/deception as reason for marriage & [45] \\
\hline & No HIV testing because Church and husband don't allow & {$[31,45]$} \\
\hline & No family planning allowed & {$[31,45,47]$} \\
\hline & No immunization allowed & [45] \\
\hline & Not allowed to go to hospitals and clinics & {$[31,45]$} \\
\hline & Polygyny common & {$[25,31,36,38,45,47]$} \\
\hline & Wife inheritance & [36] \\
\hline & Competing value system of church and school & {$[25,36]$} \\
\hline & Number of wives increases status in church & [36] \\
\hline & Failed virginity test leads to forced marriage with older man & {$[25]$} \\
\hline & Individual's responsibility compromised by Holy Spirit & [36] \\
\hline & Use of biomedicine is sign of lack of faith & {$[12,31]$} \\
\hline & Doctrinal support of high fertility & [31] \\
\hline & Dual behaviour by church members & [25] \\
\hline & accessing modern biomedical health services secretively & [25] \\
\hline
\end{tabular}




\begin{tabular}{|c|c|c|}
\hline Codes & Key Findings & Studies \\
\hline \multirow{8}{*}{ Self-condemnation } & Increase in acceptance of Health services without church support & [25] \\
\hline & Allopathic approach heathen, of the devil, putting men above God & [25] \\
\hline & Aids is a worldly disease not in church & [25] \\
\hline & Low knowledge of HIV & [47] \\
\hline & Self-image as possessed by evil spirits or being bewitched & [30] \\
\hline & Thieves like us cannot go to church & [30] \\
\hline & Negative religious-spiritual self-image & [30] \\
\hline & Negative implications on psychological functioning, moral behaviours, and social relations & [30] \\
\hline \multirow[t]{2}{*}{ Traditionalists } & $\begin{array}{l}\text { Higher risk behaviour amongst Traditionalists could reflect health beliefs founded on } \\
\text { Ancestral spirits and witchcraft - rather than Western explanations of sickness }\end{array}$ & [8] \\
\hline & Adolescent HIV prevalence higher in indigenous populations & [48] \\
\hline \multirow[t]{2}{*}{ Abstinence only } & Facts about HIV and AIDS underemphasized in education & {$[29,49]$} \\
\hline & Adolescents cannot disclose sexual activity & [41] \\
\hline \multirow[t]{4}{*}{ Barrier to health } & Religion as barrier to health care in Zimbabwe & {$[31,12]$} \\
\hline & Not able to take tablets during fasting times & {$[12]$} \\
\hline & PrEP use is a challenge in most churches & [41] \\
\hline & Condom use is anti-Christian & [40] \\
\hline \multirow[t]{13}{*}{ HIV/AIDS Stigma } & HIV related to sexual immorality & $\begin{array}{l}{[12,18,25,26,28,29,35,} \\
41,50]\end{array}$ \\
\hline & gendered and spiritualised ideas about 'blame', 'transmission' and 'treatment' & {$[18,32]$} \\
\hline & HIV related to prostitution & {$[6,27,41,28]$} \\
\hline & Idea of individual destiny & {$[27]$} \\
\hline & Patriarchal forms of social control inherited from colonialism & [6] \\
\hline & It is the guilty one who gets sick & [28] \\
\hline & Guilty of breaking rules- mainly women are guilty & [28] \\
\hline & Leading to exclusion from church membership & [35] \\
\hline & Suffering from AIDS is sign of lack of faith & [35] \\
\hline & HIV caused by demonic forces & [25] \\
\hline & Aids as worldly disease not affecting church members & [25] \\
\hline & Mukondombera $=$ fatal disease & [26] \\
\hline & HIV is disease of women (=weak) & [51] \\
\hline \multirow[t]{3}{*}{ Homophobia } & Homosexuality is sin & [17] \\
\hline & Reproduction is part of marriage - increases stigma & [17] \\
\hline & Religion strong driver of the perceived stigma & [17] \\
\hline \multirow[t]{3}{*}{ Ubuntu } & riddled with patriarchal and oppressive elements that disadvantage women & [35] \\
\hline & practices that fuelled HIV spread & [35] \\
\hline & values human touch leading to heightened risk of infection & [35] \\
\hline Medical work as & Doctor sees medical work as a tool of evangelism & [35] \\
\hline \multirow[t]{3}{*}{ Evangelism } & blurring the line between medical care and proselytizing & [35] \\
\hline & Duality of accountability (mission and state) & [35] \\
\hline & Churches did not reach out to members of other churches & [25] \\
\hline \multicolumn{3}{|c|}{ Category: root causes beliefs, norms attitudes } \\
\hline \multirow[t]{8}{*}{ Pluralistic medical approach } & Bio-psycho-social-spiritual understanding of health: & \\
\hline & Choice of treatment depends on (accessibility, affordability, efficacy, cause) & {$[4,18,26,28,31-33]$} \\
\hline & If treatment option does not give relief, alternative explanations and treatment are adopted & {$[4,20,33]$} \\
\hline & Herbal remedies used to alleviate discomforts caused by adverse drug reactions of ART & [21] \\
\hline & TP blend traditional practices with Christian concepts & [33] \\
\hline & Going to hospital is last resort for serious illness & [4] \\
\hline & Complementary use of medicine is common & {$[4,18,20,26,28,32,33]$} \\
\hline & Medical pluralism can cause delay in care & {$[4,20]$} \\
\hline \multirow{2}{*}{$\begin{array}{l}\text { Health decision is family } \\
\text { affair }\end{array}$} & Early infant circumcision not only decided by parents & [42] \\
\hline & $\begin{array}{l}\text { Decision making is sequential and slow } \\
\text { wellness is derived from the role of family, community, and the spiritual world }\end{array}$ & $\begin{array}{l}{[20,33]} \\
{[18]}\end{array}$ \\
\hline \multirow{7}{*}{$\begin{array}{l}\text { Endemic problem-solving } \\
\text { Mechanisms }\end{array}$} & Chief's granary & [14] \\
\hline & volunteerism embedded in Shona culture & [14] \\
\hline & Idiom: "do not laugh when your neighbour is in trouble" & [14] \\
\hline & cultural ethos of Ubuntu fostered social cohesion & [14] \\
\hline & Pre-colonial Africans were self-sustained & [33] \\
\hline & Utanu- refusal to accept ill health- positive philosophy of life & [33] \\
\hline & $\begin{array}{l}\text { Sexual offence reparation in the form of 'mwombe nemwana wayo' [two head of cattle] } \\
\text { serves as prophylaxis }\end{array}$ & [53] \\
\hline \multirow{4}{*}{ Patriarchy } & proper healing is holistic=harmony and correct relationship with the spiritual worlds & [18] \\
\hline & central role of polygyny within Shona religion & {$[8,26,35,53]$} \\
\hline & Women cannot decide autonomously on health and sex & {$[18,33,47,50,53,54]$} \\
\hline & Women are voiceless & [54] \\
\hline
\end{tabular}




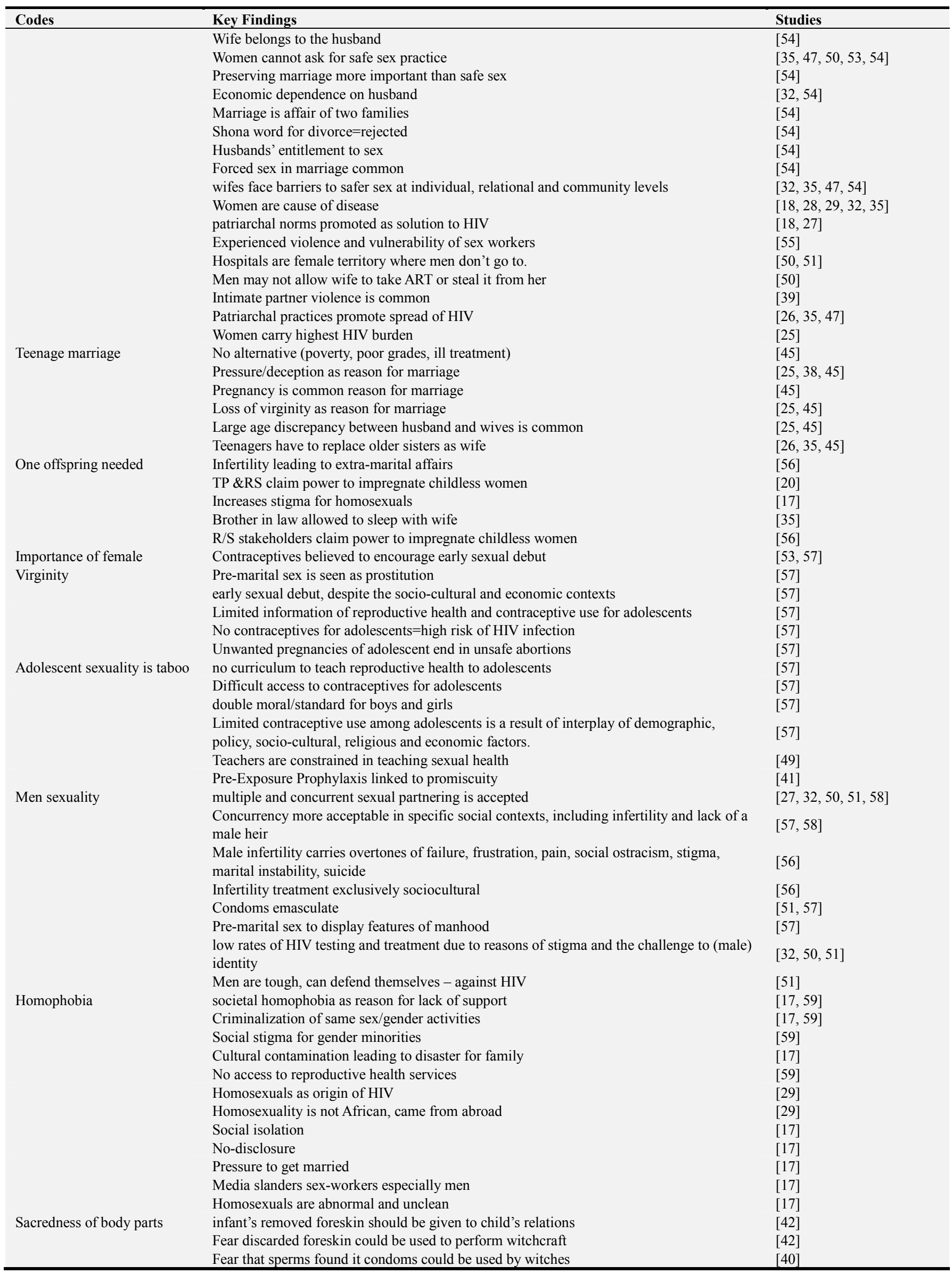




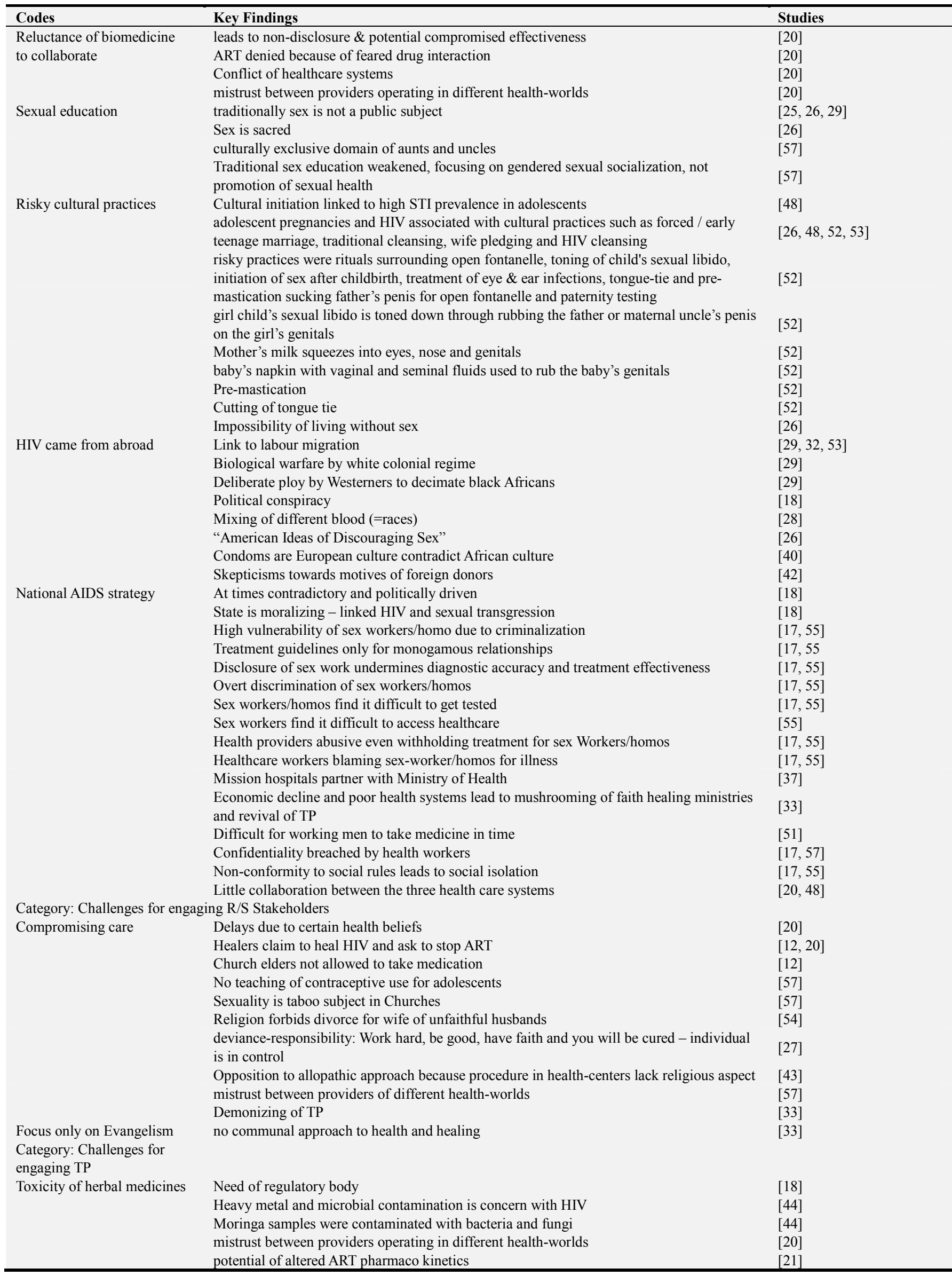




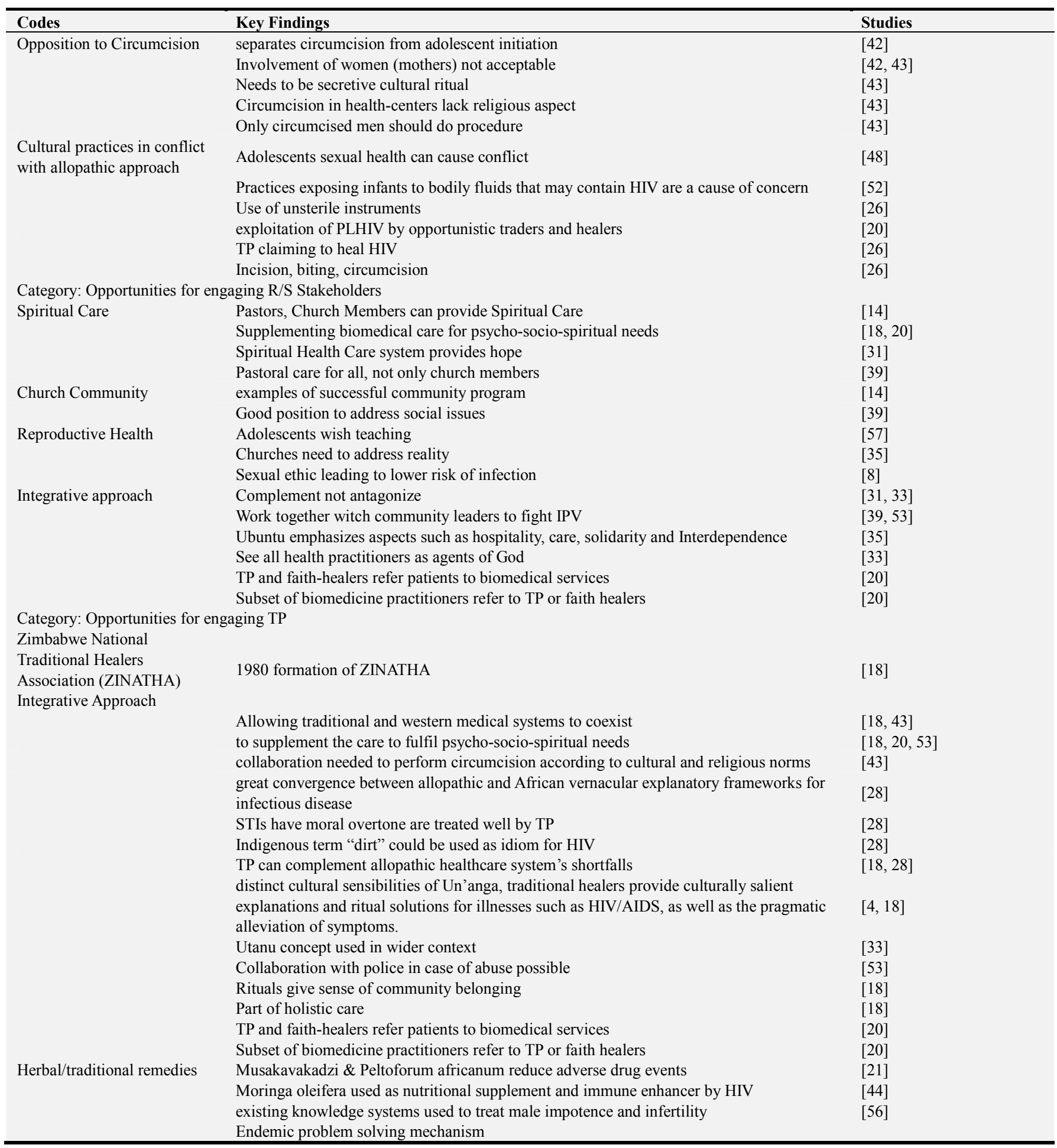

These findings were further summarized and synthetized in Figure 2. The aim of this next synthesis is to illustrate the social, cultural, and religious context of the experience of living with HIV in Zimbabwe. Deterring and enhancing R/S and TP factors influencing HIV patients need to be understood and seen in this unique context. Figure 2 illustrates the influence of $\mathrm{R} / \mathrm{S}$ and $\mathrm{TP}$ on the physical, psychological, spiritual, and social wellbeing of HIV patients and their access to reproductive health information and services, their compliance with HIV therapy and the risk of HIV infection. This Figure illustrated the medical relevance of $\mathrm{R} / \mathrm{S}$ and $\mathrm{TP}$ issues. 


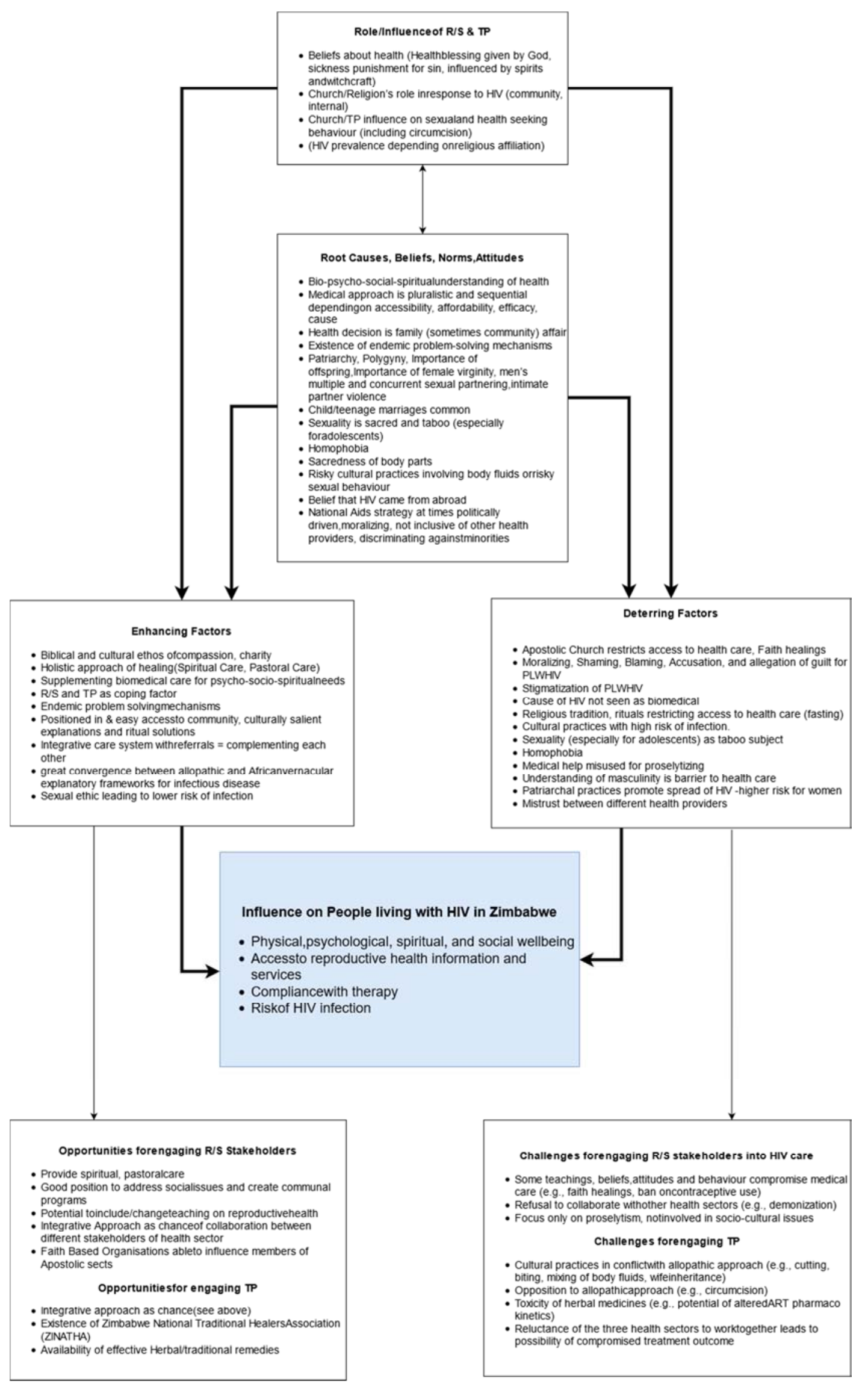

Figure 2. Summary of the findings in the socio, cultural and religious context of PLWHIV in Zimbabwe. 
Figure 2 confirms the medical relevance of R/S issues and TP. This is not surprising to most of the individual authors of the included studies. This is what many of them have tried to show in their own studies. By giving an overview of the findings of all relevant studies published in the last 11 years, the claim of medical relevance of $\mathrm{R} / \mathrm{S}$ and $\mathrm{TP}$ was endorsed. This scoping review allowed to go even a step further. Analyzing the data of all 46 records combined in Table $2+$ Figure 2 made it possible to recognize formal relations (recurring patterns, units of social organization, as well as cause and effect relations and/or social mechanisms). This helped to identify three main areas of concern (=red flags), where R/S and TP influence and shape underlying beliefs, norms, and attitudes that conflict with the allopathic medical approach and compromise the therapy outcome (shown in Figure 3 at the end):

The bio-psycho-social-spiritual understanding of health and illness is crucial to the Zimbabwean health system. The allopathic medical approach does not meet all aspects of that holistic understanding. Therefore, people use the religious and/or traditional health system to supplement allopathic therapy or choose the health system according to their perceived need. The parallel use of the three health systems can lead to concurrency, delayed access to allopathic health care, increased suffering, and compromised therapy outcome.

Patriarchal norms were long promoted as a solution to HIV. The records in this scoping review demonstrate the opposite. Patriarchal norms act as barriers to HIV care and increase the risk of becoming infected by HIV. Arguably, they are the source of much suffering for men, women, and children.

Cultural, religious, and societal norms of sexuality are very relevant in the Zimbabwean context. Sexuality is sacred, a taboo subject, moralized, and for some PLWHIV criminalized, and stigmatized.
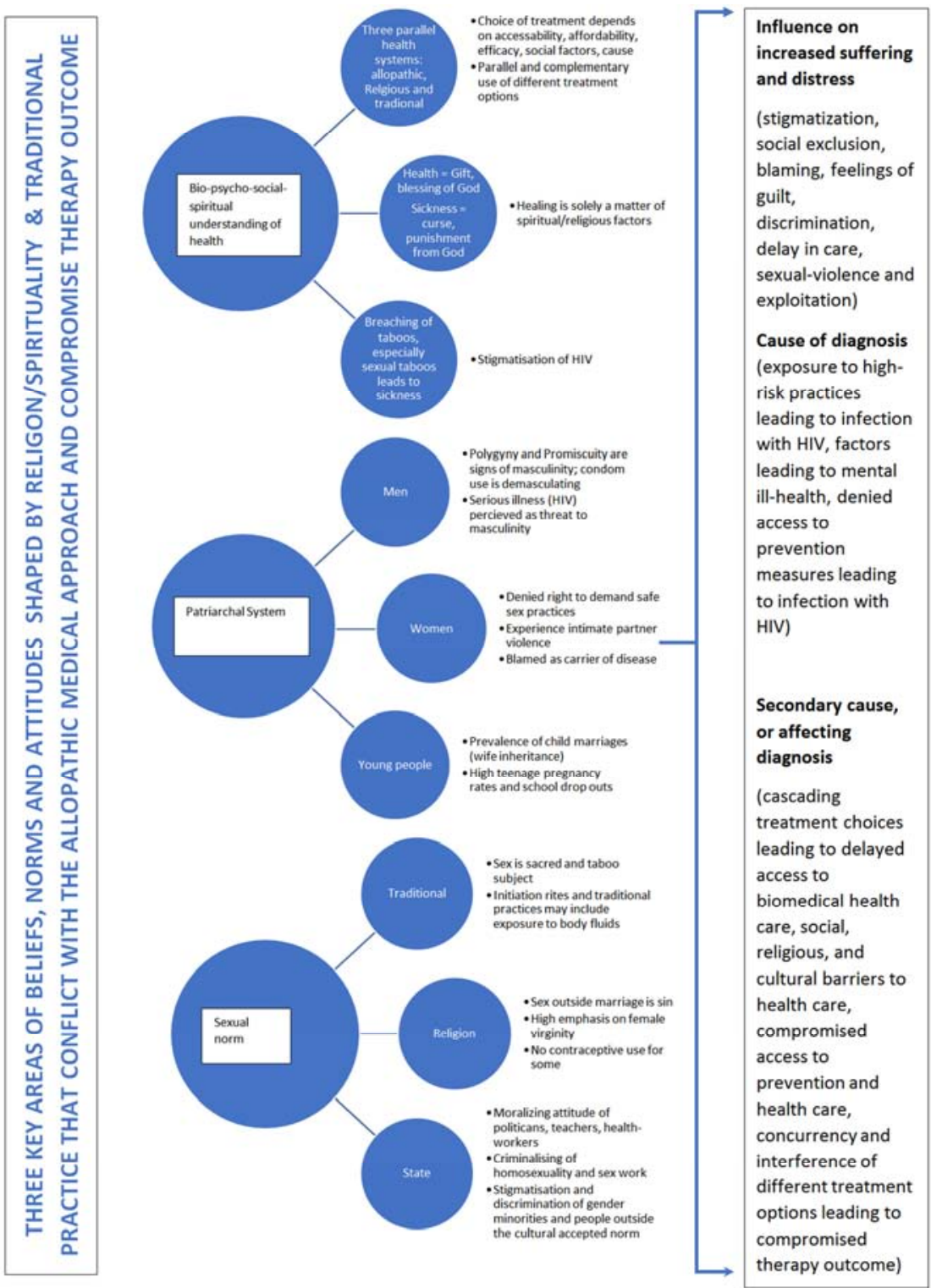

Figure 3. Underlying beliefs, root causes and attitudes leading to increased suffering, or being cause or secondary cause of a HIV infection, or affecting the diagnosis of HIV. 


\section{Discussion}

Puchalski's argument of the medical relevance of R/S in case it is the cause or secondary cause of a disease, increases the suffering, or interferes with the treatment [23] and the claim of Kendrick's recently published systematic Literature review of studies in the USA that $\mathrm{R} / \mathrm{S}$ can be a barrier or a facilitator to treatment for HIV, [60] were used to code and group the content of the 46 records (Table 2). The synthesis of these findings enabled to take out the influence of $\mathrm{R} / \mathrm{S}$ on the experience of living with HIV in Zimbabwe in general, and especially to illustrate the influence of R/S and TP on the physical and psychological wellbeing of HIV patients and the access to HIV care (Figure 2). Figure 2 describes the socio, cultural and religious context of PLWHIV in Zimbabwe and illustrates how R/S and TP play a role as facilitator and/or barrier to HIV care and wellbeing of PLWHIV and so are medically relevant.

Further synthesis of the content of the 46 records by authors from different disciplines (sociology, theology, and medicine) revealed great coherence. It was possible to recognize social relations which helped to identify three key areas where underlying beliefs, norms and attitudes directly conflict with the biomedical approach, and potentially compromise the therapy outcome (Figure 3). Thus, religious, and spiritual ontological concepts are accentuated in the identified three key areas: understanding of health, the notion of patriarchy, and sexuality. To mitigate the negative impact of specific beliefs, attitudes, and social norms, religious and spiritual ontologies need to be considered, integrated, and valued equally to secular ontologies when designing health development programs. The importance of the role of religion in health development has also been pointed out by Dijik and other anthropologists, who explain that the relationship between religion and religious responses to HIV and the biomedical approach to HIV is complex, diverse, and ever changing [61].

The focus of the synthesis of this scoping review was based on Puchalski's criteria of medical relevance of R/S. This led to a one-sided emphasis on negative health impacts. However, the enhancing factors and opportunities of the contribution of R/S and TP for PLWHIV in Zimbabwe shown in Figure 2 are equally important: R/S and TP supplement the biomedical treatment by responding to the psycho, social, and spiritual needs of PLWHIV. Spirituality plays a key role in coping. Mutambara has already shown this in one of her previous publications [62]. The importance of religious coping is widely acknowledged and was also pointed out in a recently published study from a Brazilian context [63]. Furthermore, Simmons explains that there is a great convergence between biomedical and African vernacular explanatory frameworks for infectious disease [28]. Thus, secular, and religious/spiritual ontologies do not need to clash but may together form a common basis for future health development. Figure 2 also shows that religious, spiritual, and traditional communities and practices provide a sense of belonging and mutual support. They are often the most accessible, culturally relevant, and affordable way of getting help. Such positive impacts of R/S on PLWHIV have also been shown in other studies, like in a recently published scoping review by Vigliotti and others. They found that more than half of the studies in their review documented a positive/protective association between religion, faith, spirituality, and HIV prevention activities [64].

Hence, the findings of this scoping review demonstrate that $\mathrm{R} / \mathrm{S}$ and TP influence PLWHIV in positive and negative ways and that religious and spiritual ontologies are to be taken seriously. This is in line with, Pool's and other anthropologists' call for equal appreciation and consideration of religious and secular ontologies in health development projects. They see an urgent need for a development dialogue that draws on various ontologies and that understands religion as an integral part of such a meta-ontology [65].

The WHO Bangkok Charter for Health Promotion in a Globalized World declared in 2005 that health promotion should offer an inclusive concept of health, encompassing emotional and spiritual well-being. The WHO traditional medicine strategy 2014-2023 acknowledges the importance of traditional medical practice and its contribution to health and wellbeing and a people centred healthcare [67]. The findings of this scoping review should be interpreted in this context. By portraying the importance of Religion/Spirituality including traditional beliefs and practices in the context of HIV in Zimbabwe, they underline the importance of an inclusive, value-driven approach to health development that duly respects an integral part of religious and spiritual ontologies and so becomes more people centred.

\section{Conclusion}

Religion and spirituality (including traditional practice) play an important role in the life of PLWHIV in Zimbabwe. $\mathrm{R} / \mathrm{S}$ and TP influence the health, wellbeing, and access to care in positive and negative ways. The findings of this scoping review ask for twofold action: Firstly, future health development programs should consider and integrate religious/spiritual ontologies alongside secular ontologies to avoid competitive approaches and compromised therapy outcomes. Secondly, religious stakeholders, traditional practitioners, and biomedical experts need to evaluate their own approach and teaching individually and in their communities. The three health-systems (religious, traditional, biomedical) in Zimbabwe have the potential to compliment and/or supplement each other's shortfalls. Together they can form a holistic system of care for people living with HIV in Zimbabwe. Collaboration between the three systems is needed to reduce concurrency, mistrust, and compromised therapy outcomes. Together they can achieve what neither could alone: Ending the AIDS epidemic as a public health threat by 2030 (third Sustainable Development Goal). 


\section{Appendix}

Doku Suchstring

Pubmed

(20210208; 616 hits)

((religion [MeSH Terms] OR "Religion and Medicine" [Mesh] OR medicine, african traditional [MeSH Terms] OR spiritual therapies [MeSH Terms] OR occultism [MeSH Terms] OR superstitions [MeSH Terms] OR pastoral care [MeSH Terms] OR "Chaplaincy Service, Hospital" [Mesh] OR guilt [MeSH Terms] OR spirituality [MeSH Terms] OR social stigma [MeSH Terms] OR social norm [MeSH Terms] OR morals [MeSH Terms] OR culture [MeSH Terms] OR social behavior [MeSH Terms] OR Religion and Psychology [MeSH Terms] OR complementary therapies [MeSH Terms] OR polygamy [MeSH Terms] OR patriarchy [MeSH Terms] OR guilt [tiab] OR gender [tiab] OR social representations [tiab] OR spirituality [tiab] OR attitud* [tiab] OR ethnic* [tiab] OR religi* [tiab] OR practitioner* [tiab] OR practice* [tiab] OR denomination* [tiab] OR preach* [tiab] OR prayer [tiab] OR prayers [tiab] OR church [tiab] OR churches [tiab] OR ruvheneko [tiab] OR Christ* [tiab] OR catholic* [tiab] OR protestant* [tiab] OR bapti* [tiab] OR spirit* [tiab] OR shaman* [tiab] OR faith* [tiab] OR heal* [tiab] OR tradition* [tiab] OR nanga [tiab] OR n'anga [tiab] OR spell [tiab] OR witch* [tiab] OR ritual [tiab] OR myth* [tiab] OR belief [tiab] OR beliefs [tiab] OR believ* [tiab] OR apostolic [tiab] OR prophet* [tiab] OR sect [tiab] OR sects [tiab] OR ancest* [tiab] OR sin [tiab] OR demon* [tiab] OR theolog* [tiab] OR islam* [tiab] OR muslim [tiab] OR bible [tiab] OR Quran [tiab] OR hindu [tiab] OR buddhis* [tiab] demon* [tiab] OR meditation [tiab] OR chanting [tiab] OR purification [tiab] OR occult [tiab] OR Occultis* [tiab] OR satan* [tiab] OR magic* [tiab] OR "cast out" [tiab] OR "casted out" [tiab] OR bewitched [tiab] OR mapositori [tiab] OR omen [tiab] OR holy [tiab] OR evil [tiab] OR goblin [tiab] OR goblins [tiab] OR curse [tiab] OR Johane Masowe [tiab] OR apostle [tiab] OR apostles [tiab] OR priest [tiab] OR priests [tiab] OR pastor* [tiab] OR elder [tiab] OR elders [tiab] OR supernatural [tiab] OR shrine [tiab] OR altar [tiab] OR mirac* [tiab] OR doctrine [tiab] OR preach* [tiab] OR pentecostal* [tiab] OR gospel [tiab] OR missionar* [tiab] OR indigen* [tiab] OR Jesus [tiab] OR God [tiab] OR Allah [tiab] OR Buddha [tiab] OR omen [tiab] OR omens [tiab] OR vapostori [tiab] OR white garment [tiab] OR methodist [tiab] OR Zion [tiab] OR African tradit* [tiab] OR evangeli* [tiab] OR Jehovah [tiab] OR magaya [tiab] OR deliverance [tiab] OR born again [tiab] OR prophecies [tiab] OR prophesy [tiab] OR worship* [tiab] OR salvation [tiab] OR jewish [tiab] OR jew [tiab] OR judaism [tiab] OR jesuit [tiab] OR chaplain [tiab] OR sermon [tiab] OR bishop [tiab] OR referent [tiab] OR herbalist [tiab] OR herbal [tiab] OR medium [tiab] OR totem [tiab] OR mutopa [tiab] OR makumbi [tiab] OR mishonga [tiab] OR mapipi [tiab] OR hun'anga [tiab] OR kusvikiro [tiab] OR shave [tiab] OR mudzimu [tiab] OR svikiro [tiab] OR charm [tiab] OR charms [tiab] OR mystic* [tiab] OR taboo [tiab] OR exorcis* [tiab] OR Sorcer* [tiab] OR Superstiti* [tiab] OR Pastoral [tiab] OR Chaplaincy [tiab]
OR chapel [tiab] OR moral* [tiab] OR values [tiab] OR rites [tiab] OR polygamy [tiab] OR misogyny [tiab] OR ubuntu [tiab] OR patriarchy [tiab] OR fidelity [tiab] OR world view [tiab] OR custom [tiab] OR customs [tiab])

AND (HIV infections [MeSH Terms] OR "HIV Seropositivity" [Mesh] OR Attitude to Health [MeSH Terms] OR sexual behavior [MeSH Terms] OR sex education [MeSH Terms] OR condoms [MeSH Terms] OR sex offenses [MeSH Terms] OR domestic violence [MeSH Terms] OR intimate partner violence [MeSH Terms] OR sexually transmitted diseases [MeSH Terms] OR HIV [tiab] OR human immunodeficiency virus [tiab] OR Acute Retroviral Syndrome [tiab] OR HIV/AIDS [tiab] OR AIDS [tiab] OR acquired immunodeficiency syndrome [tiab] OR PLHIV [tiab] OR PWA [tiab] OR PLWA [tiab] OR PLWHA [tiab] OR ARV [tiab] OR antiretroviral* [tiab] OR anti-retroviral therapy [tiab] OR ART [tiab] OR condom [tiab] OR condoms [tiab] OR health [tiab] OR intergenerational relationships [tiab] OR child marriage [tiab] OR sex [tiab] OR sexual* [tiab] OR domestic violence [tiab] OR partner violence [tiab])

AND (zimbabwe* [tiab] OR harare [tiab] OR shona [tiab] OR ndebele [tiab] OR n'debele [tiab] OR venda [tiab] OR tonga [tiab] OR rhodesia [tiab] OR bulawayo [tiab] OR manicaland [tiab] OR masvingo [tiab] OR matabele [tiab] OR Gweru [tiab] OR Chiota [tiab] OR zimbabwe [AD] OR Zimbabwe [MeSH Terms]))

AND 2010/01/01:3000/12/31 [edat]

ATLA

(20210208; 22 hits)

((DE "Religion" OR DE "Anthropology of religion" OR DE "Architecture and religion" OR DE "Art and religion" OR DE "Civil religion" OR DE "Religion and culture" OR $\mathrm{DE}$ "Economics and religion" OR DE "Education and religion" OR DE "Ethics and religion" OR DE "Geography and religion" OR DE "Hallucinogenic drugs and religious experience" OR DE "International relations and religion" OR DE "Irreligion" OR DE "Language and religion" OR DE "Law and religion" OR DE "Religion and literature" OR DE "Medicine and religion" OR DE "Mental health and religion" OR DE "Music and religion" OR DE "Mythology" OR DE "Pantheism" OR DE "Parapsychology and religion" OR DE "Religion and politics" OR DE "Psychiatry and religion" OR DE "Psychoanalysis and religion" OR DE "Religious articles" OR DE "Religion and science" OR DE "Socialism and religion" OR DE "Religion and sociology" OR DE "Religion and state" OR DE "Symbolism in religion" OR DE "Syncretism" OR DE "Technology and religion" OR DE "Theology" OR DE "War -- Religious aspects" OR DE "Indifferentism (Religion)" OR DE "Trinities" OR DE "Salvation" OR DE "Implicit religion" OR DE "Postsecularism" OR DE "Archaeology and religion" OR DE "National socialism and religion" OR DE "Offenses against religion" OR DE "Monotheism" OR DE "Superstition" OR DE "Supernatural" OR DE "Indigenous peoples -- Religion" OR DE "Religious pluralism" OR DE "Temperance and religion" OR DE "Puritan movements" OR DE "Word 
(Theology)" OR DE "Worship" OR DE "Visions" OR DE "Animism" OR DE "Faith" OR DE "Idols and images" OR DE "Mysteries, Religious" OR DE "Polytheism" OR DE "Positivism" OR DE "Proselytizing" OR DE "Religious life" OR DE "Religious thought" OR DE "Women and religion" OR DE "Spirituality" OR DE "Messianism") OR (DE "Spiritualism" OR DE "Caodaism" OR DE "Channeling (Spiritualism)" OR DE "Levitation" OR DE "Mediums" OR DE "New Age movement" OR DE "Occult sciences" OR DE "Spirit writings" OR DE "Seances" OR DE "Materialization" OR DE "Spirit portraits" OR DE "Soul mates") OR (DE "Occult sciences" OR DE "Alchemy" OR DE "Clairvoyance" OR DE "Demonology" OR DE "Divination" OR DE "Gematria" OR DE "Geomancy" OR DE "Hermetism" OR DE "Kundalini" OR DE "Mediums" OR DE "Satanism" OR DE "Witchcraft") OR (DE "Religion, Primitive" OR DE "Ancestor worship" OR DE "Animism" OR DE "Celts -Religion" OR DE "Cultus, Roman" OR DE "Fetishism" OR DE "Fire-worshipers" OR DE "High gods" OR DE "Household shrines" OR DE "Incubation (Religion)" OR DE "Mana" OR DE "Mother goddesses" OR DE "Nativistic movements" OR DE "Orientation (Religion)" OR DE "Priests (Primitive religions)" OR DE "Shamanism" OR DE "Sky gods" OR DE "Superstition" OR DE "Taboo" OR DE "Totemism") OR (DE "Supernatural" OR DE "Miracles" OR DE "Demonology" OR DE "Divination" OR DE "Prophecies" OR DE "Psychical research" OR DE "Spirits" OR DE "Superstition" OR DE "Revelation" OR DE "Marvelous, The" OR DE "Automatic writing") OR (DE "Church work" OR DE "Basic Christian communities" OR DE "Chaplains, Hospital" OR DE "Church management" OR DE "Church officers" OR DE "Church renewal" OR DE "Clergy" OR DE "Evangelistic work" OR DE "Institutionalism (Religion)" OR DE "Interdenominational cooperation" OR DE "Laity" OR DE "Leadership, Religious" OR DE "Ministry" OR DE "Missions" OR DE "Missions, City" OR DE "Pastoral associates" OR DE "Pastoral counseling" OR DE "Pastoral theology" OR DE "Public relations -- Churches" OR DE "Revivals" OR DE "Rural clergy" OR DE "Sunday schools" OR DE "Visitations (Church work)" OR DE "Women in church work" OR DE "Church-night services" OR DE "Church entertainments" OR DE "Internet in church work" OR DE "Retirees in church work" OR DE "Youth in church work" OR DE "Pastoral care" OR DE "Recreation in church work" OR DE "Married people in church work" OR DE "Mentoring in church work" OR DE "Telephone in church work" OR DE "Books in church work") OR (DE "Chaplains" OR DE "Chaplains, Court" OR DE "Chaplains, Hospital" OR DE "Chaplains, Industrial" OR DE "Chaplains, Military" OR DE "Chaplains, Nursing home" OR DE "Chaplains, Police" OR DE "Chaplains, Prison" OR DE "Chaplains, School" OR DE "Chaplains, University and college") OR (DE "Guilt" OR DE "Shame") OR (DE "Social stratification") OR (DE "social norms") OR (DE "literature and morals") OR (DE "Culture" OR DE "Acculturation" OR DE "Art and culture" OR DE "Biculturalism" OR DE "Cross-cultural studies" OR DE
"Ecology and culture" OR DE "Intercultural communication" OR DE "Language and culture" OR DE "Liturgy and culture" OR DE "Material culture" OR DE "Personality and culture" OR DE "Popular culture" OR DE "Socialization" OR DE "Cultural policy" OR DE "Politics and culture" OR DE "Culture diffusion" OR DE "Subculture" OR DE "Political culture" OR DE "Cultural pluralism" OR DE "Educational anthropology" OR DE "Communication and culture") OR (DE "Psychology and religion" OR DE "Jesus Christ -Psychology" OR DE "Bible -- Psychology" OR DE "Qur an -- Psychology" OR DE "Clergy -- Psychology" OR DE "Conference proceedings -- Psychology and religion" OR DE "Missionaries -- Psychology" OR DE "Prayer -- Psychology" OR DE "Psychoanalysis and religion" OR DE "Psychology, Religious" OR DE "Religious attitudes" OR DE "Seminarians -- Psychology" OR DE "Tests and measurements in religion" OR DE "Preaching -- Psychology") OR (DE "Alternative medicine" OR DE "Holistic medicine" OR DE "Homeopathy" OR DE "Medicine, Magic" OR DE "Medicine, Oriental" OR DE "Mental healing" OR DE "Mesmerism" OR DE "Traditional medicine" OR DE "Energy medicine") OR (DE "Polygamy" OR DE "Harems" OR DE "Polyandry") OR (DE "patriarchy") OR (TI guilt OR $\mathrm{AB}$ guilt) OR (TI gender OR AB gender) OR (TI "social representations" OR AB "social representations") OR (TI spirituality OR AB spirituality) OR (TI attitud* OR AB attitud*) OR (TI ethnic* OR AB ethnic*) OR (TI religi* OR AB religi*) OR (TI practitioner* OR AB practitioner*) OR (TI practice* OR AB practice*) OR (TI denomination* OR AB denomination*) OR (TI preach* OR AB preach*) OR (TI prayer OR AB prayer) OR (TI prayers OR AB prayers) OR (TI church OR AB church) OR (TI churches OR AB churches) OR (TI ruvheneko OR AB ruvheneko) OR (TI Christ* OR AB Christ*) OR (TI catholic* OR AB catholic*) OR (TI protestant* OR AB protestant*) OR (TI bapti* OR AB bapti*) OR (TI spirit* OR AB spirit*) OR (TI shaman* OR AB shaman*) OR (TI faith* OR AB faith*) OR (TI heal* OR AB heal*) OR (TI tradition* OR AB tradition*) OR (TI nanga OR AB nanga) OR (TI n'anga OR AB n'anga) OR (TI spell OR AB spell) OR (TI witch* OR AB witch*) OR (TI ritual OR AB ritual) OR (TI myth* OR AB myth*) OR (TI belief OR AB belief) OR (TI beliefs OR AB beliefs) OR (TI believ* OR AB believ*) OR (TI apostolic OR AB apostolic) OR (TI prophet* OR AB prophet*) OR (TI sect OR AB sect) OR (TI sects OR AB sects) OR (TI ancest* OR AB ancest*) OR (TI sin OR AB sin) OR (TI demon* OR AB demon*) OR (TI theolog* OR AB theolog*) OR (TI islam* OR AB islam*) OR (TI muslim OR AB muslim) OR (TI bible OR AB bible) OR (TI Quran OR AB Quran) OR (TI hindu OR AB hindu) OR (TI "buddhis* demon*" OR AB "buddhis* demon*") OR (TI meditation OR AB meditation) OR (TI chanting OR AB chanting) OR (TI purification OR AB purification) OR (TI occult OR AB occult) OR (TI Occultis* OR AB Occultis*) OR (TI satan* OR AB satan*) OR (TI magic* OR AB magic*) OR (TI "cast out" OR AB "cast out") OR (TI "casted out" OR AB "casted out") OR (TI bewitched OR AB bewitched) OR (TI mapositori OR AB mapositori) OR (TI 
omen OR AB omen) OR (TI holy OR AB holy) OR (TI evil OR AB evil) OR (TI goblin OR AB goblin) OR (TI goblins OR AB goblins) OR (TI curse OR AB curse) OR (TI "Johane Masowe" OR AB "Johane Masowe") OR (TI apostle OR AB apostle) OR (TI apostles OR AB apostles) OR (TI priest OR AB priest) OR (TI priests OR AB priests) OR (TI pastor* OR AB pastor*) OR (TI elder OR AB elder) OR (TI elders OR AB elders) OR (TI supernatural OR AB supernatural) OR (TI shrine OR AB shrine) OR (TI altar OR AB altar) OR (TI mirac* OR AB mirac*) OR (TI doctrine OR AB doctrine) OR (TI preach* OR AB preach*) OR (TI pentecostal* OR AB pentecostal*) OR (TI gospel OR AB gospel) OR (TI missionar* OR AB missionar*) OR (TI indigen* OR AB indigen*) OR (TI Jesus OR AB Jesus) OR (TI God OR AB God) OR (TI Allah OR AB Allah) OR (TI Buddha OR AB Buddha) OR (TI omen OR AB omen) OR (TI omens OR AB omens) OR (TI vapostori OR AB vapostori) OR (TI "white garment" OR AB "white garment") OR (TI methodist OR AB methodist) OR (TI Zion OR AB Zion) OR (TI "African tradit*" OR AB "African tradit*") OR (TI evangeli* OR AB evangeli*) OR (TI Jehovah OR AB Jehovah) OR (TI magaya OR AB magaya) OR (TI deliverance OR AB deliverance) OR (TI "born again" OR AB "born again") OR (TI prophecies $\mathrm{OR} A B$ prophecies) OR (TI prophesy OR AB prophesy) OR (TI worship* OR AB worship*) OR (TI salvation $\mathrm{OR} A B$ salvation) $\mathrm{OR}$ (TI jewish $\mathrm{OR} A B$ jewish) OR (TI jew OR AB jew) OR (TI judaism OR AB judaism) OR (TI jesuit OR AB jesuit) OR (TI chaplain OR AB chaplain) OR (TI sermon OR AB sermon) OR (TI bishop OR $\mathrm{AB}$ bishop) OR (TI referent $\mathrm{OR} A B$ referent) OR (TI herbalist OR AB herbalist) OR (TI herbal OR AB herbal) OR (TI medium OR AB medium) OR (TI totem OR AB totem) OR (TI mutopa OR AB mutopa) OR (TI makumbi OR AB makumbi) OR (TI mishonga OR AB mishonga) OR (TI mapipi OR AB mapipi) OR (TI hun'anga OR AB hun'anga) OR (TI kusvikiro OR AB kusvikiro) OR (TI shave OR AB shave) OR (TI mudzimu OR AB mudzimu) OR (TI svikiro OR AB svikiro) OR (TI charm OR AB charm) OR (TI charms OR AB charms) OR (TI mystic* OR AB mystic*) OR (TI taboo OR AB taboo) OR (TI exorcis* OR AB exorcis*) OR (TI Sorcer* OR AB Sorcer*) OR (TI Superstiti* OR AB Superstiti*) OR (TI Pastoral OR AB Pastoral) OR (TI Chaplaincy OR AB Chaplaincy) OR (TI chapel OR AB chapel) OR (TI moral* OR AB moral*) OR (TI values $\mathrm{OR} A B$ values) $\mathrm{OR}$ (TI rites $\mathrm{OR} A B$ rites) $\mathrm{OR}$ (TI polygamy OR $A B$ polygamy) OR (TI misogyny OR AB misogyny) OR (TI ubuntu OR AB ubuntu) OR (TI patriarchy OR AB patriarchy) OR (TI fidelity OR AB fidelity) OR (TI "world view" OR AB "world view") OR (TI custom OR AB custom) OR (TI customs OR AB customs))

AND ((DE "Hiv Infections" OR DE "Hiv Infections -Africa" OR DE "Hiv Infections -- Congresses" OR DE "HIV Infections -- England -- London" OR DE "Hiv Infections -Peru" OR DE "Hiv Infections -- Prevention -- Congresses" OR DE "Hiv Infections -- Prevention -- Moral and ethical aspects" OR DE "Hiv Infections -- Prevention -- Religious aspects -- Catholic Church" OR DE "Hiv Infections --
Prevention -- Religious aspects -- Christianity" OR DE "Hiv Infections -- Statistics" OR DE "Hiv Infections -- Testing" OR DE "Hiv Infections -- Transmission -- Thailand") OR (DE "HIV-positive persons" OR DE "AIDS (Disease) -Patients" OR DE "Church work with HIV-positive persons") OR (DE "Health behavior" OR DE "Patient refusal of treatment") OR (DE "Sex customs" OR DE "Premarital sex" OR DE "Puberty rites" OR DE "Sex in literature") OR (DE "Sexual ethics" OR DE "Abortion" OR DE "Adultery" OR DE "Bioethics" OR DE "Celibacy" OR DE "Incest" OR DE "Premarital sex" OR DE "Prostitution" OR DE "Chastity" OR DE "Sexual consent") OR (DE "Sex education" OR DE "Sex education -- Religious aspects" OR DE "Sex education - Religious aspects -- Catholic Church" OR DE "Sex education -- Religious aspects -- Christianity" OR DE "Sex education -- Religious aspects -- Islam" OR DE "Sex education -- Religious aspects -- Judaism" OR DE "Sex education for youth -- Great Britain" OR DE "Sex education for youth -- Religious Aspects") OR (DE "Condoms" OR DE "Condoms -- Complications") OR (DE "Sex crimes" OR DE "Bigamy" OR DE "Incest" OR DE "Pedophilia" OR DE "Rape" OR DE "Sodomy" OR DE "Fornication" OR DE "Child sexual abuse" OR DE "Adultery") OR (MH "domestic violence+") OR ((DE "Sexually transmitted diseases" OR DE "Syphilis") OR (DE "Sexual health")) OR (DE "Hygiene, Sexual") OR (TI HIV OR AB HIV) OR (TI "human immunodeficiency virus" OR AB "human immunodeficiency virus") OR (TI "Acute Retroviral Syndrome" OR AB "Acute Retroviral Syndrome") OR (TI "HIV/AIDS" OR AB "HIV/AIDS") OR (TI AIDS OR AB AIDS) OR (TI "acquired immunodeficiency syndrome" $\mathrm{OR} \quad \mathrm{AB}$ "acquired immunodeficiency syndrome") OR (TI PLHIV OR AB PLHIV) OR (TI PWA OR AB PWA) OR (TI PLWA OR AB PLWA) OR (TI PLWHA OR AB PLWHA) OR (TI ARV OR AB ARV) OR (TI antiretroviral* OR AB antiretroviral*) OR (TI "anti-retroviral therapy" OR AB "anti-retroviral therapy") OR (TI ART OR AB ART) OR (TI condom OR AB condom) OR (TI condoms OR AB condoms) OR (TI health OR AB health) OR (TI "intergenerational relationships" OR AB "intergenerational relationships") OR (TI "child marriage" OR AB "child marriage") OR (TI sex OR AB sex) OR (TI sexual* OR AB sexual*) OR (TI "domestic violence" OR AB "domestic violence") OR (TI "partner violence" OR AB "partner violence"))

AND ((TI zimbabwe* OR AB zimbabwe*) OR (TI harare OR AB harare) OR (TI shona OR AB shona) OR (TI ndebele OR AB ndebele) OR (TI n'debele OR AB n'debele) OR (TI venda OR $A B$ venda) OR (TI tonga OR AB tonga) OR (TI rhodesia OR $A B$ rhodesia) OR (TI bulawayo OR AB bulawayo) OR (TI manicaland OR AB manicaland) OR (TI masvingo $\mathrm{OR} A B$ masvingo) $\mathrm{OR}$ (TI matabele $\mathrm{OR} A B$ matabele) OR (TI Gweru OR AB Gweru) OR (TI Chiota OR AB Chiota) OR (PP Zimbabwe) OR (DE "Zimbabwe" OR DE "Bulawayo (Zimbabwe)" OR DE "Zimbabwe Assemblies of God Africa" OR DE "Zimbabwe Council of Churches" OR DE "Zimbabwean literature" OR DE "Zimbabweans")))

Limiters - Year Published: 2010-3000 


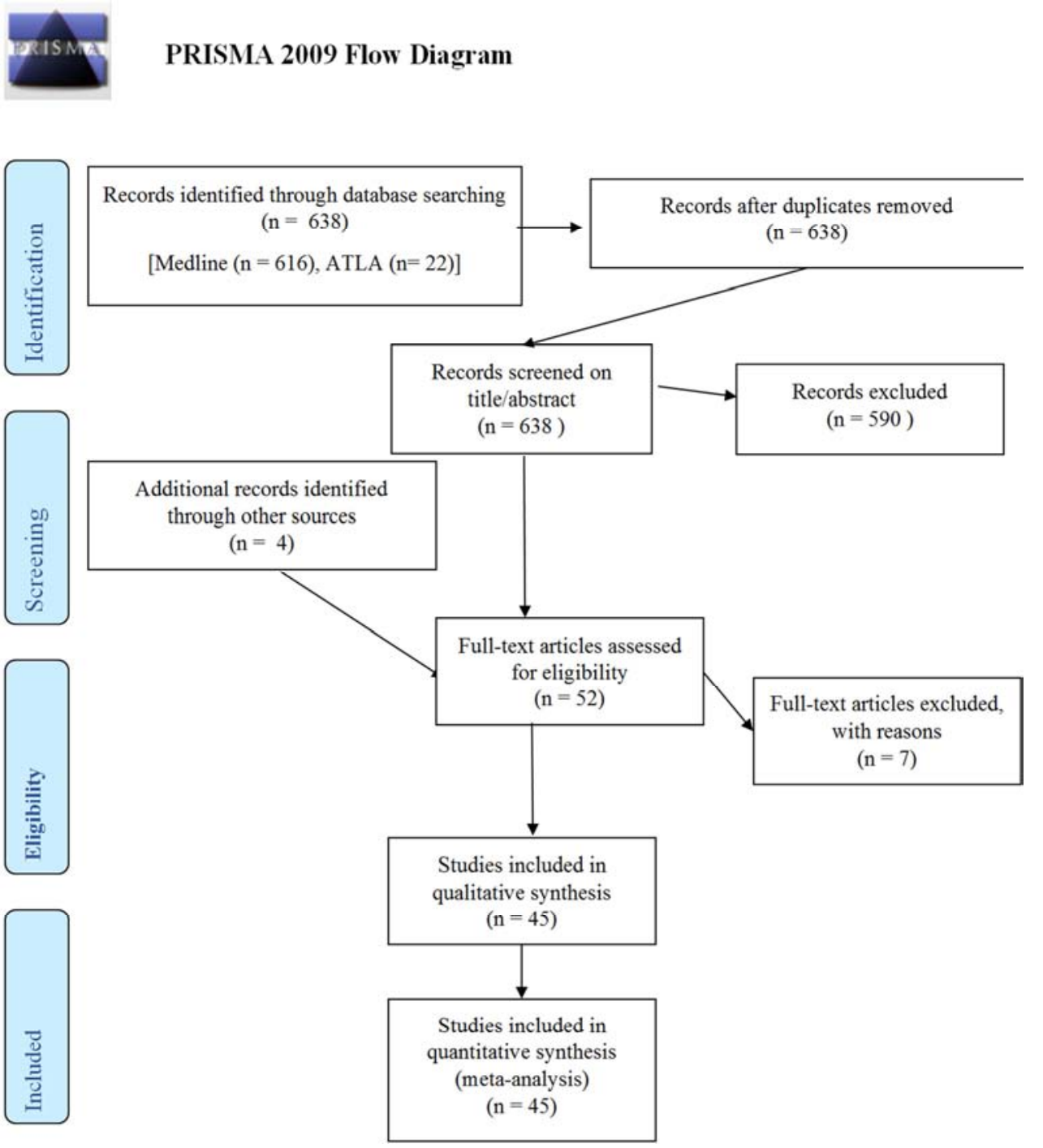

Figure 4. PRISMA Flow diagram.

\section{References}

[1] Unaids, 'UNAIDS Countryreport 2019'. Accessed: Nov. 16, $2020 . \quad$ [Online]. Available: https://www.unaids.org/sites/default/files/country/documents/ ZWE_2019_countryreport.pdf.

[2] R. Makurumidze et al., 'Retention and predictors of attrition among patients who started antiretroviral therapy in Zimbabwe's national antiretroviral therapy programme between 2012 and 2015', PLOS ONE, vol. 15, no. 1, p. e0222309, Jan. 2020, doi: 10.1371/journal.pone.0222309.

[3] T. Shoko, 'Traditional Herbal Medicine and Healing in Zimbabwe', J. Tradit. Med. Clin. Naturop., vol. 07, no. 01, 2018, doi: 10.4172/2573-4555.1000254.

[4] T. N. Taylor, "'Because I was in pain, I just wanted to be treated": competing therapeutic goals in the performance of healing HIV/AIDS in rural Zimbabwe', J. Am. Folk-Lore, vol. 123, no. 489, pp. 304-328, 2010.

[5] ZIMSTAT, 'Zimbabwe Demographic and Health Survey
2010-11, 2012, [Online]. Available: https://dhsprogram.com/pubs/pdf/Fr254/Fr254.pdf.

[6] S. O'Brien and A. Broom, 'HIV in (and out of) the clinic: Biomedicine, traditional medicine and spiritual healing in Harare', SAHARA-J J. Soc. Asp. HIVAIDS, vol. 11, no. 1, pp. 94-104, Jan. 2014, doi: 10.1080/17290376.2014.938102.

[7] O. Tapera et al., 'Sociodemographic inequities in cervical cancer screening, treatment and care amongst women aged at least 25 years: evidence from surveys in Harare, Zimbabwe', BMC Public Health, vol. 19, no. 1, p. 428, Dec. 2019, doi: 10.1186/s12889-019-6749-6.

[8] R. Manzou, C. Schumacher, and S. Gregson, 'Temporal Dynamics of Religion as a Determinant of HIV Infection in East Zimbabwe: A Serial Cross-Sectional Analysis', PLoS $O N E$, vol. 9, no. 1, p. e86060, Jan. 2014, doi: 10.1371/journal.pone. 0086060 .

[9] 'Four voices, one concern - Addressing "faith-healing only" in context of HIV', World Council of Churches. https://www.oikoumene.org/news/four-voices-one-concernaddressing-faith-healing-only-in-context-of-hiv (accessed Nov. $16,2020)$. 
[10] W. Mavhu et al., 'Effect of a differentiated service delivery model on virological failure in adolescents with HIV in Zimbabwe (Zvandiri): a cluster-randomised controlled trial', Lancet Glob. Health, vol. 8, no. 2, pp. e264-e275, Feb. 2020, doi: 10.1016/S2214-109X(19)30526-1.

[11] "'Facing the storm of HIV, we can move together, be agents of change", World Council of Churches. https://www.oikoumene.org/news/facing-the-storm-of-hiv-wecan-move-together-be-agents-of-change (accessed Nov. 16, 2020).

[12] J. Mutambara, T. Sodi, J. Mtemeri, and M. Makomo, 'Harmonizing religion and health: an exploration of religious reasons for defaulting ARVs among people living with HIV and AIDS in Gweru, Zimbabwe', AIDS Care, pp. 1-6, Feb. 2020, doi: 10.1080/09540121.2020.1724255.

[13] F. Becker, Aids and religious practice in Africa. Leiden: Brill, 2009.

[14] C. T. Dzimiri, P. Dzimiri, and K. Batisai, 'Fighting against HIV and AIDS within a resource constrained rural setting: a case study of the Ruvheneko Programme in Chirumhanzu, Zimbabwe', SAHARA-J J. Soc. Asp. HIVAIDS, vol. 16, no. 1, pp. 25-34, Jan. 2019, doi: 10.1080/17290376.2019.1605537.

[15] R. Kidman and A. Violari, 'Dating Violence Against HIVInfected Youth in South Africa: Associations With Sexual Risk Behavior, Medication Adherence, and Mental Health', JAIDS J. Acquir. Immune Defic. Syndr., vol. 77, no. 1, pp. 64-71, Jan. 2018, doi: 10.1097/QAI.0000000000001569.

[16] D. S. Simmons, Modernizing Medicine in Zimbabwe: HIV/AIDS and Traditional Healers. Nashville: Vanderbilt University Press, 2012.

[17] E. Y. Tsang, S. Qiao, J. S. Wilkinson, A. L. Fung, F. Lipeleke, and X. Li, 'Multilayered Stigma and Vulnerabilities for HIV Infection and Transmission: A Qualitative Study on Male Sex Workers in Zimbabwe', Am. J. Mens Health, vol. 13, p. 155798831882388, Jan. 2019, doi: $10.1177 / 1557988318823883$.

[18] K. Batisai, 'Towards an integrated approach to health and medicine in Africa', SAHARA-J J. Soc. Asp. HIVAIDS, vol. 13, no. 1 , pp. 113-122, Jan. 2016, doi: 10.1080/17290376.2016.1220323.

[19] P. Rohleder, L. Swartz, S. C. Kalichman, and L. C. Simbayi, Eds., HIV/AIDS in South Africa 25 Years On. New York, NY: Springer New York, 2009.

[20] M. Moshabela et al., 'Traditional healers, faith healers and medical practitioners: the contribution of medical pluralism to bottlenecks along the cascade of care for HIV/AIDS in Eastern and Southern Africa', Sex. Transm. Infect., vol. 93, no. Suppl 3, p. e052974, Jul. 2017, doi: 10.1136/sextrans-2016052974.

[21] T. Mudzviti, C. C. Maponga, S. Khoza, Q. Ma, and G. D. Morse, 'The Impact of Herbal Drug Use on Adverse Drug Reaction Profiles of Patients on Antiretroviral Therapy in Zimbabwe', AIDS Res. Treat., vol. 2012, pp. 1-4, 2012, doi: $10.1155 / 2012 / 434171$

[22] M. Alexio and M. Precious, 'Understanding contributions of traditional healers to the prevention, care and support in the fight against HIV and AIDS Pandemic in Kariba, Zimbabwe', Int. J. Sociol. Anthropol., vol. 6, no. 4, pp. 136-145, Apr. 2014, doi: 10.5897/IJSA2013.0513.
[23] C. M. Puchalski, 'Restorative medicine', in Oxford Textbook of Spirituality in Healthcare, Oxford University Press, 2012, pp. 197-210.

[24] Mazvita Machinga, 'Religion, Health, and Healing in the Traditional Shona Culture of Zimbabwe', Practical Matters $\begin{array}{llll}\text { Journal, } & \text { Mar. } & 011 .\end{array}$ http://practicalmattersjournal.org/2011/03/01/religion-healthhealing/ (accessed Apr. 06, 2021).

[25] J. Musevenzi, 'The African Independent Apostolic Church's Doctrine under Threat: The Emerging Power of Faith-based Organisations' Interventions and the Johanne Marange Apostolic Church in Zimbabwe', J. Study Relig., vol. 30, no. 2 pp. 178-206, 2017, doi: 10.17159/2413-3027/2017/v30n2a8.

[26] Tabona Shoko, 'Mukondombera.pdf'. Journal for the Study of the Religions of Africa and its Diaspora, 1 no 1 Aug 2015, p 517, Aug. 01, 2015.

[27] S. O'Brien and A. Broom, 'HIV in Harare: The role and relevance of social stigma', Afr. J. AIDS Res., vol. 13, no. 4, pp. 339-349, Oct. 2014, doi: 10.2989/16085906.2014.961941.

[28] D. Simmons, 'The role of ethnography in STI and HIV/AIDS education and promotion with traditional healers in Zimbabwe', Health Promot. Int., vol. 26, no. 4, pp. 476-483, Dec. 2011, doi: 10.1093/heapro/dar004.

[29] T. Nyatsanza and L. Wood, 'Problematizing official narratives of HIV and AIDS education in Scotland and Zimbabwe', SAHARA-J J. Soc. Asp. HIVAIDS, vol. 14, no. 1, pp. 185-192, Jan. 2017, doi: 10.1080/17290376.2017.1394908.

[30] S. Mhizha, 'The Religious-Spiritual Self-Image and Behaviours Among Adolescent Street Children in Harare, Zimbabwe', J. Relig. Health, vol. 54, no. 1, pp. 187-201, Feb. 2015, doi: 10.1007/s10943-013-9799-6.

[31] D. Munyaradzi Kenneth, M. Marvellous, M. Stanzia, and D.M. Memory, 'Praying until Death: Apostolicism, Delays and Maternal Mortality in Zimbabwe', PLOS ONE, vol. 11, no. 8, p. e0160170, Aug. 2016, doi: 10.1371/journal.pone.0160170.

[32] S. O'Brien and A. Broom, 'Gender, culture and changing attitudes: experiences of HIV in Zimbabwe', Cult. Health Sex., vol. 15, no. 5, pp. 583-597, May 2013, doi: 10.1080/13691058.2013.776111.

[33] S. Chirongoma, 'Exploring the impact of economic and sociopolitical development on people's health and well-being: A case study of the Karanga people in Masvingo, Zimbabwe', HTS Teol. Stud. Theol. Stud., vol. 72, no. 4, p. 9 pages, May 2016, doi: 10.4102/hts.v72i4.3491.

[34] D. D. Hallfors et al., 'Preventing HIV by providing support for orphan girls to stay in school: does religion matter?', Ethn. Health, vol. 18, no. 1, pp. 53-65, Feb. 2013, doi: 10.1080/13557858.2012.694068.

[35] C. Banda and S. Mudzanire, 'Supplementing the lack of ubuntu? The ministry of Zimbabwe's Mashoko Christian Hospital to people living with HIV and AIDS in challenging their stigmatisation in the church', HTS Teol. Stud. Theol. Stud., vol. 75, no. 4, Sep. 2019, doi: 10.4102/hts.v75i4.5468.

[36] E. Mpofu, T. M. Dune, D. D. Hallfors, J. Mapfumo, M. M. Mutepfa, and J. January, 'Apostolic faith church organization contexts for health and wellbeing in women and children', Ethn. Health, vol. 16, no. 6, pp. 551-566, Dec. 2011, doi: $10.1080 / 13557858.2011 .583639$. 
[37] I. Mhike and E. K. Makombe, 'Mission and State Health Institutions: "Invisible" Public-Private Partnerships in Zimbabwe, 1980-1999', Stud. Hist. Eccles., vol. 44, no. 1, Mar. 2018, doi: 10.25159/2412-4265/3330.

[38] F. Machingura, 'A Diet of Wives as the Lifestyle of the Vapostori Sects: The Polygamy Debate in the Face of HIV and AIDS in Zimbabwe', vol. 5, no. 2, p. 26, 2011.

[39] V. Magezi and P. Manzanga, 'COVID-19 and intimate partner violence in Zimbabwe: Towards being church in situations of gender-based violence from a public pastoral care perspective', Skriflig Luce Verbi, vol. 54, no. 1, Dec. 2020, doi: 10.4102/ids.v54i1.2658.

[40] N. Mudonhi, W. N. Nunu, B. Ndlovu, N. Khumalo, and O. Dube, 'Adolescents and Parents' Perceptions of Condom Distribution in Selected Secondary Schools in the High Density Suburbs of Bulawayo, Zimbabwe', Sex. Cult., vol. 24, no. 3, pp. 485-503, Jun. 2020, doi: 10.1007/s12119-01909642-2.

[41] J. Velloza et al., 'The influence of HIV-related stigma on PrEP disclosure and adherence among adolescent girls and young women in HPTN 082: a qualitative study', J. Int. AIDS Soc., vol. 23, no. 3, Mar. 2020, doi: 10.1002/jia2.25463.

[42] W. Mavhu et al., 'Acceptability of Early Infant Male Circumcision as an HIV Prevention Intervention in Zimbabwe: A Qualitative Perspective', PLoS ONE, vol. 7, no. 2, p. e32475, Feb. 2012, doi: 10.1371/journal.pone.0032475.

[43] K. Shumba and M. Lubombo, 'Cultural competence: a framework for promoting voluntary medical male circumcision among VaRemba communities in Zimbabwe', Afr. J. AIDS Res., vol. 16, no. 2, pp. 165-173, Apr. 2017, doi: 10.2989/16085906.2017.1337040.

[44] T. G. Monera-Penduka and Z. T. Jani, 'Quality and labeling information of Moringa oleifera products merketed for HIVinfected people in Zimbabwe', J. Public Health Afr., vol. Volume 7/618, 2016, doi: doi.org/10.4081/jphia.2016.618.

[45] D. D. Hallfors et al., "II thought if I marry the prophet I would not die": The significance of religious affiliation on marriage, HIV testing, and reproductive health practices among young married women in Zimbabwe', SAHARA-J J. Soc. Asp. HIVAIDS, vol. 13, no. 1, pp. 178-187, Jan. 2016, doi: 10.1080/17290376.2016.1245627.

[46] M. Mhaka-Mutepfa, E. Mpofu, and R. Cumming, 'Impact of Protective Factors on Resilience of Grandparent Carers Fostering Orphans and Non-Orphans in Zimbabwe', J. Aging Health, vol. 27, no. 3, pp. 454-479, Apr. 2015, doi: 10.1177/0898264314551333.

[47] M. Mapingure et al., 'Understanding HIV and associated risk factors among religious groups in Zimbabwe', BMC Public Health, vol. 21, no. 1, p. 375, Dec. 2021, doi: 10.1186/s12889021-10405-8.

[48] W. N. Nunu, L. Makhado, J. T. Mabunda, and R. T. Lebese, 'Strategies to facilitate safe sexual practices in adolescents through integrated health systems in selected districts of Zimbabwe: a mixed method study protocol', Reprod. Health, vol. 17, no. 1, p. 20, Dec. 2020, doi: 10.1186/s12978-020-0862-y.

[49] E. Mpofu, M. M. Mutepfa, and D. D. Hallfors, 'Mapping Structural Influences on Sex and HIV Education in Church and Secular Schools in Zimbabwe', Eval. Health Prof., vol. 35, no. 3, pp. 346-359, Sep. 2012, doi:

\section{$10.1177 / 0163278712443962$.}

[50] M. Skovdal, C. Campbell, C. Nyamukapa, and S. Gregson, 'When masculinity interferes with women's treatment of HIV infection: a qualitative study about adherence to antiretroviral therapy in Zimbabwe', J. Int. AIDS Soc., vol. 14, no. 1, pp. 29-29, Jan. 2011, doi: 10.1186/1758-2652-14-29.

[51] M. Skovdal, C. Campbell, C. Madanhire, Z. Mupambireyi, C. Nyamukapa, and S. Gregson, 'Masculinity as a barrier to men's use of HIV services in Zimbabwe', Glob. Health, vol. 7, no. 1, p. 13, 2011, doi: 10.1186/1744-8603-7-13.

[52] Z. Nyati-Jokomo, J. January, W. Ruparanganda, and I. Chitsike, 'Risky traditional practices and prevention of mother-to-child transmission of HIV: the case of Chiota community in Zimbabwe', AIDS Care, vol. 28, no. 1, pp. 5256, Jan. 2016, doi: 10.1080/09540121.2015.1062463.

[53] J. Marashe, 'The African traditional religious landscape: An examination of the role of traditional leaders in the fight against HIV and AIDS in Chipinge, Zimbabwe', Verbum Eccles., vol. 35 , no. 1, p. 8 pages, Jan. 2014, doi: 10.4102/ve.v35i1.871.

[54] E. Mugweni, S. Pearson, and M. Omar, 'Traditional gender roles, forced sex and HIV in Zimbabwean marriages', Cult. Health Sex., vol. 14, no. 5, pp. 577-590, May 2012, doi: $10.1080 / 13691058.2012 .671962$.

[55] F. Scorgie et al., "We are despised in the hospitals": sex workers' experiences of accessing health care in four African countries', Cult. Health Sex., vol. 15, no. 4, pp. 450-465, Apr. 2013, doi: 10.1080/13691058.2012.763187.

[56] S. Moyo, 'Indigenous knowledge systems and attitudes towards male infertility in Mhondoro-Ngezi, Zimbabwe', Cult. Health Sex., vol. 15, no. 6, pp. 667-679, Jun. 2013, doi: 10.1080/13691058.2013.779029.

[57] S. Moyo and O. Rusinga, 'Contraceptives: Adolescents' Knowledge, Attitudes and Practices. A Case Study of Rural Mhondoro-Ngezi District, Zimbabwe', Afr. J. Reprod. Health, vol. 21, no. 1, pp. 49-63, Mar. 2017, doi: 10.29063/ajrh2017/v21i1.4.

[58] W. Mavhu, L. Langhaug, S. Pascoe, J. Dirawo, and F. Cowan, 'A novel tool to assess community norms and attitudes to multiple and concurrent sexual partnering in', p. 9.

[59] A. Müller, S. Spencer, T. Meer, and K. Daskilewicz, 'The nogo zone: a qualitative study of access to sexual and reproductive health services for sexual and gender minority adolescents in Southern Africa', Reprod. Health, vol. 15, no. 1, p. 12 , Dec. 2018 , doi: $10.1186 / \mathrm{s} 12978-018-0462-2$.

[60] H. Medved Kendrick, 'Are religion and spirituality barriers or facilitators to treatment for HIV: a systematic review of the literature', AIDS Care, vol. 29, no. 1, pp. 1-13, Jan. 2017, doi: 10.1080/09540121.2016.1201196.

[61] R. van Dijk, H. Dilger, M. Burchardt, and T. Rasing, Religion and AIDS treatment in Africa: saving souls, prolonging lives. 2018. Accessed: May 18, 2021. [Online]. Available: http://www.vlebooks.com/vleweb/product/openreader?id=non e\&isbn=9781317068204.

[62] J. Mutambara and T. Sodi, 'Exploring the Role of Spirituality in Coping With War Trauma Among War Veterans in Zimbabwe', SAGE Open, vol. 8, no. 1, p. 215824401775043 , Jan. 2018, doi: 10.1177/2158244017750433. 
[63] H. L. Brito and E. M. F. Seidl, 'Resilience of People with HIV/AIDS: Infl uence of Religious Coping', Temas Em Psicol., vol. 27, no. 3, pp. 647-660, 2019, doi: 10.9788/TP2019.3-04.

[64] V. Vigliotti, T. Taggart, M. Walker, S. Kusmastuti, and Y. Ransome, 'Religion, faith, and spirituality influences on HIV prevention activities A scoping review', PLOS ONE, vol. 15, no. 6, p. e0234720, Jun. 2020, doi: 10.1371/journal.pone.0234720.
[65] F. W. Pool, 'Development Within a Religious Ontology? The Argument from Islamic Dharma', Eur. J. Dev. Res., vol. 32, no. 4, pp. 1038-1056, Sep. 2020, doi: 10.1057/s41287-01900252-0.

[66] 'The Bangkok Charter for Health Promotion in a Globalized World', Health Promot. Int., vol. 21, no. suppl_1, pp. 10-14, Dec. 2006, doi: 10.1093/heapro/dal046.

[67] World Health Organization, Ed., WHO traditional medicine strategy. 2014-2023. Geneva: World Health Organization, 2013. 